\title{
THE JOINT CROSS-SECTIONAL VARIATION OF EQUITY RETURNS AND VOLATILITIES
}

\author{
Ana González-Urteaga \\ Universidad Pública de Navarra \\ Gonzalo Rubio \\ Universidad CEU Cardenal Herrera
}

\begin{abstract}
This paper analyzes the determinants of the simultaneous cross-sectional variation of return and volatility risk premia. Independently of the model specification employed, the estimated risk premium associated with the default premium beta is always positive and statistically different from zero. Moreover, the risk premium of the market volatility risk premium beta is negative and statistically significant. However, both risk factors are priced economically and statistically differently in the volatility and return segments of the market. On average, common factors in both segments explain $90 \%$ of the variability of volatility risk premium portfolios, but only $65 \%$ of the variability of equity return portfolios.
\end{abstract}

This version: November 3, 2016

Keywords: return risk premia; volatility risk premia; linear factor models; default premium; return and volatility market segmentation

JEL classification: G12, G13

We thank Javier Gil-Bazo, Geert Bekaert, Belén Nieto, Alfonso Novales, two anonymous referees, and seminar participants at Pompeu Fabra University and CUNEF. The authors acknowledge financial support from the Ministry of Economics and Competitiveness through grant ECO2015-67035-P. In addition, Gonzalo Rubio acknowledges financial support from the Bank of Spain, and Generalitat Valenciana grant PROMETEOII/2013/015, and Ana González-Urteaga from Ministry of Economics and Competitiveness through grant ECO2016-77631-R.

Corresponding author: Gonzalo Rubio (gonzalo.rubio@uch.ceu.es). 


\section{Introduction}

This paper analyzes one clear and well defined question. Does a specific factor model of the stochastic discount factor work for both returns and volatilities? We answer this question using two complementary empirical strategies. We first analyze the joint crosssectional variation of return and volatility risk premia. Then, we provide a market segmentation test in the return and volatility segments of the market. Although we find strong signs of commonality between return and volatility risk premia, we formally reject the pricing integration of both segments and reject joint pricing models.

Understanding this simultaneous pricing, but also the statistical and economic differences in the drivers of risk premia in both the return and volatility segments of the market is the main contribution of this paper. Moreover, the use of new data to test asset pricing models alleviates the possibility that data mining drives the results. To the best of our knowledge, this is the first paper to address joint estimation of return and volatility risk premia on the same set of assets, and it presents new evidence regarding market segmentation between the return and volatility sections of the market. This joint analysis may allow discarding some risk factors proposed in the literature in explaining the average equity return premium, or the volatility premium, while providing supporting empirical evidence for other factors.

The inclusion of volatility risk premia at the joint cross-sectional variation of average returns and volatilities is a very different approach from previous studies, in which volatility is shown to be a relevant aggregate risk factor in the cross-section of expected returns. ${ }^{1}$ We therefore argue that not only is aggregate stock market volatility priced, but also shocks to idiosyncratic volatility are priced in the cross-section. This justifies cross-sectional analysis of not only average equity return premia, but also the

\footnotetext{
${ }^{1}$ The seminal paper of Ang, Hodrick, Xing, and Zhang (2006) shows that volatility risk is priced in the cross-section of equity returns. Along these lines, see also the consistent evidence provided by Campbell, Giglio, Polk, and Turley (2014), and Bali and Zhou (2016).
} 
simultaneous cross-section of volatility risk premia. The most recent theoretical motivation for the cross-sectional pricing of idiosyncratic volatility is provided by Herskovic, Kelly, Lustig, and Van Nieuwerburgh (2016) who show that firms' idiosyncratic volatility presents a strong factor structure. ${ }^{2}$ Their common idiosyncratic volatility $(C I V)$ factor is related to income risk faced by households in a model with incomplete markets and heterogeneous agents. In this context, higher idiosyncratic volatility is shown to raise the average household's marginal utility. Indeed, GonzálezUrteaga and Rubio (2016) analyze the determinants of the cross-sectional variation of the average volatility risk premia for a set of 20 portfolios sorted by volatility risk premium betas. The market volatility risk premium and, in particular, the default premium are shown to be key determinant risk factors in the cross-sectional variation of average volatility risk premium payoffs. The cross-sectional variation of risk premia reflects the different uses of volatility swaps in hedging default and the financial stress risks of the underlying components of the sample portfolios.

We assume that the stochastic discount factor (SDF), which jointly prices returns and volatility risk premia is a linear function of a set of aggregate risk factors and we test competing specifications. Using the estimation methodology recently proposed by Kan, Robotti and Shanken (2013), we show that beta with respect to market volatility risk premia and the default premium beta have statistically significant risk premia that help to explain the joint cross-sectional variation of average return and volatility risk premia. The cross-sectional $\hat{R}^{2}$ of the two-factor model is $30.2 \%$ and is statistically different from zero. The default premium factor whose estimated risk premium related to the default premium beta is as high as $7.2 \%$ on annual basis, seems to be the key

\footnotetext{
${ }^{2}$ Duarte, Kamara, Siegel, and Sun (2014) also show that the pricing of the U.S. idiosyncratic volatility risk is due to a common idiosyncratic factor that explain about a third of the variability in idiosyncratic volatility. At the international level, Bekaert, Hodrick, and Zhang (2012) show that idiosyncratic volatility is significantly correlated across countries due to growth opportunities, U.S. market volatility, and the risk sensitivity to business cycles.
} 
factor in explaining the joint cross-section of returns and volatilities. These empirical results hold even if we allow for errors-in-variable and potential misspecification of the models.

We also consider extensions of the two-factor model using the leverage factor of Adrian, Etula, and Muir (2014) and alternative measures of funding liquidity. In particular, we consider the TED spread and the funding liquidity proxy of Fontaine and García (2012). Although these measures help to explain the cross-sectional variation of returns and volatilities, it is important to note that, in all cases, both the market volatility risk premium and the default premium remain statistically different from zero.

Even more importantly, once the joint evidence is established, we also test for market segmentation, and analyze whether the risk premia of priced factors are equal in both the volatility and return segments of the market. We show that both the default and market volatility risk factors are priced economically and statistically differently in both segments. Moreover, the profitability factor of Fama and French (2015) is significantly priced in the volatility segment but not in the equity return section of the market. In addition, when sorting assets by the volatility risk premium beta to create 40 volatility and return portfolios, we find that, on average, common factors in both segments explain $90 \%$ of the variability of the volatility risk premium portfolios, but only $65 \%$ of the variability of the equity return portfolios. When we do the reverse exercise and sort assets by the stock market beta to create the 40 portfolios generating market beta spread, common factor explains, on average, $82 \%$ of the variability of the volatility risk premium portfolios, but only $59 \%$ of the variability of return portfolios. Interestingly, these results do not seem to depend on the way we sort portfolios to generate either volatility or market beta spread. Overall, our evidence implies that we reject the null hypothesis of market integration. 
This paper proceeds as follows. Section 2 describes the pricing framework and the alternative asset pricing models that we employ in studying the joint cross-sectional variation of average return and volatility risk premia. Section 3 describes the data. Section 4 briefly discusses the model-free implied variance and the estimation of the volatility risk premium $(V R P)$ at the portfolio level. Section 5 presents the basic characteristics of the $20 \mathrm{VRP}$ beta-sorted portfolios and the corresponding 20 equity return portfolios. Section 6 discusses the econometric strategy and reports our simultaneous empirical findings for equity returns, and both volatility and variance risk premia. Section 7 discusses market segmentation, and the sources of pricing of our 40 portfolios distinguishing the effects from the 20 volatility and return portfolios. Finally, Section 8 presents our conclusions.

\section{Linear Factor Models of the Stochastic Discount Factor for Equity Returns and}

\section{Volatilities}

In a volatility swap, the buyer of a forward contract receives at expiration a payoff equals to the difference between the annualized volatility of stock returns and the fixed swap rate. The swap rate is chosen such that the contract has zero present value, which implies that the volatility swap rate represents the risk-neutral expected value of the realized return volatility:

$$
E_{t}^{Q}\left(R V_{t, t+\tau}^{a}\right)=S W_{t, t+\tau}^{a}
$$

where $E_{t}^{Q}($.$) is the time t$ conditional expectation operator under some risk-neutral measure $Q, R V_{t, t+\tau}^{a}$ is the realized volatility of asset (or portfolio) $a$ between $t$ and $t$ $+\tau$, and $S W_{t, t+\tau}^{a}$ is the delivery price for the volatility or the volatility swap rate on the underlying asset $a$. The volatility risk premium of asset $a$ is defined as 


$$
V R P_{t, t+\tau}^{a}=E_{t}^{P}\left(R V_{t, t+\tau}^{a}\right)-E_{t}^{Q}\left(R V_{t, t+\tau}^{a}\right)
$$

where $E_{t}^{P}\left(R V_{t, t+\tau}^{a}\right)$ is the expected value of volatility under the physical measure $P$.

The fundamental pricing equation under the same $\mathrm{SDF}, M_{t, t+\tau}$, prices equity return and volatility risk premia:

$$
E_{t}^{P}\left\lfloor M_{t, t+\tau}\left(R V R P_{t, t+\tau}^{a}\right)\right\rfloor=0
$$

where $R V R P_{t, t+\tau}^{a}$ is a vector containing both the return and volatility risk premia of asset $a$. We assume that the SDF, which jointly prices return and volatility risk premia is a linear function of a set of aggregate risk factors:

$$
M_{t, t+\tau}=a+b_{1} F_{1 t, t+\tau}+b_{2} F_{2 t, t+\tau}+\ldots+b_{K} F_{K t, t+\tau}
$$

Our empirical strategy employs the classic beta specification given by

$$
E\left(R V R P_{t, t+\tau}^{a}\right)=\lambda_{0}+\lambda_{1} \beta_{1}^{a}+\lambda_{2} \beta_{2}^{a}+\ldots+\lambda_{K} \beta_{K}^{a}
$$

where $E\left(R V R P_{t, t+\tau}^{a}\right)$ is the unconditional expected value vector of both return and volatility risk premia of asset $a$, and $\beta_{k}^{a}$ is a vector containing the exposures of the return and volatility risk premia to factor risk $k$. The main idea of the paper is to test whether the same factor model of the SDF prices simultaneously returns and volatilities (and variances). The chosen factors are based on the previous empirical evidence regarding both the cross-sectional behavior of average returns, and the recent results about the cross-sectional variation of volatility risk premia.

Regarding the cross-section of equity returns, under linear empirical pricing models, Maio and Santa Clara (2012) show that a three-factor model with market excess return, high-minus-low $(H M L)$ factor of Fama and French (1993, FF hereafter), and momentum factor (MOM) of Carhart (1997) consistently meet the ICAPM restrictions across alternative sorting portfolio procedures. The risk premium associated with the 
beta of the small-minus-big ( $S M B)$ factor of FF (1993) is not statistically different from zero in their sample. Kan, Robotti, and Shanken (2013, KRS hereafter) favor the threefactor model of FF (1993) and the five-factor ICAPM model of Petkova (2006), which, in addition to excess market return, includes aggregate dividend yield, one-month Treasury bill rate, slope of the Treasury yield curve, and corporate bond default spread or default premium, to proxy for changes in the future opportunity set. More recently, FF $(2014,2015)$ show that a five-factor model that expands their popular three-factor model with profitability (robust minus weak, $R M W$ ) and investment (aggressive minus conservative, $C M A$ ) factors explains anomalies associated with low betas, low share repurchases, and low volatility assets relative to high betas, high repurchases, and high volatility securities. ${ }^{3}$ On the other hand, momentum cannot be explained unless the $M O M$ factor is included in the cross-section. In addition, we employ the quality-minusjunk (QMJ) factor of Asnes, Frazzini and Pedersen (2014). These authors define a quality stock as an asset for which an investor would be willing to pay a higher price. These are stocks that are safe (low required rate of return), profitable (high return on equity), growing (high cash flow growth), and well managed (high dividend payout ratio). Asnes, Frazzini and Pedersen (2014) show that the $Q M J$ factor, that buys highquality stocks and shorts low-quality (junk) stocks, earns significant risk-adjusted returns not only in the U.S. market, but also in 24 other countries.

Pastor and Stambaugh (2003) and Acharya and Pedersen (2005), among other authors, show that market-wide illiquidity is a priced factor across alternative liquidityand volatility-sorted portfolios. Indeed, Amihud, Hameed, Kang and Zhang (2015) examine the illiquidity premium in stock markets across 45 countries and show that the

\footnotetext{
${ }^{3}$ Novy-Marx (2013) also discusses the relevance of the profitability factor in pricing the cross-section of average stock returns.
} 
average illiquidity return premium across countries is positive and significant, after controlling for the FF (1993) factors and the momentum factor of Carhart (1997).

Finally, funding liquidity has become a key source of aggregate risk in recent papers on asset pricing. Brunnermeier and Pedersen (2009) model the liquidity spiral with interconnections between market and funding liquidity using the channel of margin requirements, and Garleanu and Pedersen (2011) show precisely how leverage constraints (or funding constraints) affect asset prices. The empirical evidence supports the presence of funding liquidity across a wide range of securities. Frazzini and Pedersen (2014) show that leverage constraints are strongly and significantly reflected in the return differential between leveraged low-beta stocks and de-leveraged high-beta stocks. These authors argue that the positive and highly significant risk-adjusted returns relative to traditional asset pricing models shown by portfolios sorted by the level of market beta are explained by shadow cost-of-borrowing constraints. The authors illustrate their argument by proposing a market neutral betting-against-beta $(B A B)$ factor consisting of long levered low-beta stocks and short de-levered high-beta securities. The authors provide convincing evidence that the $B A B$ factor generates high and consistent performance in each of the major global markets and asset classes, and that the results are independent of the asset pricing model employed in the analysis of performance.

With respect to the cross-section of volatility risk premia, González-Urteaga and Rubio (2016) show that the market volatility risk premium and, especially, the default premium are key risk factors in the cross-sectional variation of average volatility risk premium payoffs. The exposure associated with these two factors significantly explains as much as $51.4 \%$ of the cross-sectional variation of volatility risk premia. They argue that the cross-sectional variation of risk premia reflects a very different behavior of the underlying components of their sample portfolios with respect to credit or financial 
stress that generates a significant dispersion of the volatility swap pricing of these securities.

Note that the two factors employed in the paper by González-Urteaga and Rubio (2016) can also be justified using the previous available empirical evidence. First, the use of the market volatility risk premium may be justified by noting that Bali and Zhou (2016) argue that economic uncertainty proxied by the market variance risk premium is a significant factor in size, book-to-market, momentum, and industry return portfolios. The fact that the variance risk premium seems to be priced in the cross-section can be rationalized since the variance risk premium predicts aggregate stock market returns as shown by Bollerslev, Tauchen, and Zhou (2009), and further discussed by Bekaert and Hoerova (2014). This suggests that the market variance risk premium satisfies the necessary condition of predictability to be a candidate factor in a theoretically motivated ICAPM. Secondly, the economic rationale of the model with the default premium comes from the findings of Zhou (2010) and Wang, Zhou, and Zhou (2013), who show that the firm-level variance risk premium has significant explanatory power for credit default swap spreads over and above the market variance risk premium and the VIX. Predictive ability increases as the credit quality of the credit default swap underlying companies deteriorates. Along these lines, it is interesting to note that $\mathrm{Cao}, \mathrm{Yu}$, and Zhong (2010) argue that credit default swaps are similar to out-of-the-money put options and show that the volatility risk premium embedded in options prices covaries with credit default swap spreads. As discussed below, the strategy employed to estimate synthetic volatility swap rates, based on the procedure proposed by Britten-Jones and Neuberger (2002) and Jiang and Tian (2005), gives more weight to a particular option the higher the degree to which the option is out-of-the-money. 


\section{Data}

We employ daily data from OptionMetrics for S\&P 100 Index options and for individual options on all stocks included in the S\&P 100 Index at any point during the sample period January 1996 to February 2011. This yields a total of 181 stocks used in our estimations. From the OptionMetrics database, we obtain all put and call options on the individual stocks and on the index with time to maturity $\tau$ between 6 days and 60 days. Given that the options are American-style, it is convenient to work with shortterm maturity options, for which the early exercise premium tends to be negligible. ${ }^{4} \mathrm{We}$ select the best bid and ask closing quotes to calculate the mid-quotes as the average of bid and ask prices, not actual transaction prices, to avoid the well-known bid-ask bounce problem described by Bakshi, Cao, and Chen (1997). In selecting our final option sample, we apply the usual filters. We discard options with zero open interest, zero bid prices, missing delta or implied volatility, and negative implied volatility. Regarding the exercise level, we follow Jiang and Tian (2005) and Driessen, Maenhout, and Vilkov (2009) and exclude in-the-money options. We employ calls with a delta lower than 0.5 and puts with a delta higher (less negative) than -0.5. In addition, we ignore options with extreme moneyness, that is, puts with a delta higher than -0.05 and calls with a delta lower than 0.05 .

As our option data, the market return for the S\&P 100 Index and individual stock returns and dividends are also obtained from OptionMetrics, while portfolio return data are from Kenneth French's website. In particular, we collect monthly data on the valueweighted stock market portfolio return, risk-free rate, $S M B$ and $H M L$ FF risk factors, and the $M O M$ factor. The $Q M J$, market-wide liquidity, and $B A B$ factors are obtained from Andrea Frazzini's, Lubos Pastor's and Larse Pedersen's websites, respectively.

\footnotetext{
${ }^{4}$ See the evidence reported by Driessen, Maenhout, and Vilkov (2009), who employ a similar database.
} 
In addition, yields for 10-year government bonds, one-month T-bills, and Moody's Baa corporate bonds are obtained from the Federal Reserve Statistical Release. The default premium (DEF) is the difference between Moody's yield on Baa corporate bonds and the 10-year government bond yield.

\section{The Construction of Portfolios with Volatility Risk Premium and Rates of}

\section{Return Data}

Britten-Jones and Neuberger (2002) were the first to derive the model-free implied variance under diffusion assumptions. They obtain the risk-neutral expected integrated variance over the life of an option contract when prices are continuous and variance is stochastic. Jiang and Tian (2005) extend these authors's work to show that their method is also valid in a jump- diffusion framework and, therefore, their methodology is considered to be a model-free procedure..$^{5}$

We calculate the model-free implied variance denoted $\operatorname{MFIVAR}_{t, t+\tau}^{a}$ by the following integral over a continuum of strikes:

$$
\operatorname{MFIVAR}_{t, t+\tau}^{a}=2 \int_{0}^{\infty} \frac{C_{t, t+\tau}^{a}(K) / B(t, t+\tau)-\max \left(S_{t}^{a} / B(t, t+\tau)-K, 0\right)}{K^{2}} d K
$$

where $C_{t, t+\tau}^{a}(K)$ is the spot price at time $t$ of a $\tau$-maturity call option on either an asset or index $a$ with strike $K, B(t, t+\tau)$ is the time $t$ price of a zero-coupon bond that pays $\$ 1$ at time $t+\tau$, and $S_{t}^{a}$ is the spot price of asset $a$ at time $t$ minus the present value of

\footnotetext{
${ }^{5}$ Despite the fact that the model-free implied variance proposed by Jiang and Tiang (2005) is generally accepted in the literature, Martin (2013) argues that, under stress market conditions, like October 1987 and the fall of 2008, there is no known way to replicate the payoff of a variance swap. This may be particularly severe for individual stocks which may experience more frequent and larger jumps than market indices. Martin (2013) proposes the "simple variance swap", which can be hedged at discrete points even if the underlying's asset price jumps. Future research should investigate the differences between both approaches for the market and individual variance risk premia. As discussed by GonzálezUrteaga and Rubio (2016), we are relatively more conservative than Jiang and Tiang (2005) when addressing the truncation error associated with the tails of the distribution across strikes.
} 
all expected future dividends to be paid before the option maturity. Specific implementation of equation (6) follows the approach of Jiang and Tian (2005), and the details are described in González-Urteaga and Rubio (2016).

For each time-to-maturity from six days to 60 days, we calculate the model-free implied variance each day for each underlying asset that has at least three available options outstanding, using all the available options at time $t$. The window from six days to 60 days corresponds to the maximum range of time to maturity we allow in the necessary interpolation to have enough options every day in the sample with 30 days to maturity. Therefore, at each time $t$, we focus on a 30-day horizon maturity, interpolated when necessary using the nearest maturities following the procedure of Carr and $\mathrm{Wu}$ (2009). Finally, we use the square root of the model-free implied variance to approximate the model-free annualized implied volatility as ${ }^{6}$

$$
M F I V_{t, t+\tau}^{a}=\sqrt{M F I V A R_{t, t+\tau}^{a}}
$$

For each day in the sample period, and for each asset, we also calculate the realized variance over the same period as that for which implied variance is obtained for that day, that is, for 30 days, requiring that no more than 14 returns be missing from the sample:

$$
R V A R_{t, t+\tau}^{a}=\frac{1}{\tau} \sum_{s=1}^{\tau} R_{t+s}^{2}
$$

where $R V A R_{t, t+\tau}^{a}$ is the realized variance of asset $a$, and $R$ denotes the rate of return adjusted by dividends and splits. As before, we annualized the realized variance and take the square root to obtain the realized volatility:

\footnotetext{
${ }^{6}$ Carr and $\mathrm{Wu}$ (2009), among many other papers, employ variance swaps rather than volatility swaps. As discussed later in the paper, it is important to recognize that there is a difference between the value of a variance swap and the value of a volatility swap that depends on the volatility of volatility of the underlying asset. This implies that the use of equation (7) introduces a bias that may potentially distort the results. In Section 7 below, we show that the cross-sectional empirical results using either volatility or variance swaps are robust to alternative pricing specifications.
} 


$$
R V_{t, t+\tau}^{a}=\sqrt{R V A R_{t, t+\tau}^{a}}
$$

Finally, for each day, and for each asset and the index, we calculate the volatility risk premium at the 30-day horizon as the difference between the corresponding realized and model-free implied volatility:

$$
V R P_{t, t+\tau}^{a}=R V_{t, t+\tau}^{a}-M F I V_{t, t+\tau}^{a}
$$

Given the estimated volatility risk premium for each day and every asset in the sample, including the market index, we next construct $20 \mathrm{VRP}$ beta-sorted portfolios using the following procedure. We estimate rolling $V R P$ betas for each month using daily data over the preceding month on the individual $V R P$ and the market $V R P$. Each month, we rank all $V R P$ betas and construct 20 equally weighted $V R P$ beta-sorted portfolios with volatility risk premium data. Portfolio 1 (P1VRP hereafter) contains the most negative VRP betas, while Portfolio 20 (P20VRP hereafter) includes the most positive VRP betas. The components of all portfolios are updated every month during the sample period. All portfolios have approximately the same number of securities, with an average of 5.3 securities per portfolio, and the asset must have at least 15 daily observations to be included in the portfolios. Given this procedure, for each month during the sample period, we can identify the underlying components of the $20 \mathrm{VRP}$ beta-sorted portfolios, and calculate the corresponding portfolio returns. We now have 20 additional portfolios of returns with the same components of the $20 \mathrm{VRP}$ beta-sorted portfolios. Therefore, we end up with 40 portfolios, 20 with volatility risk premium data, and the other 20 with rates of returns. Note that for each of the 40 portfolios, the underlying components are the same in both sets of portfolios. Our initial crosssectional analysis is based on these 40 portfolios.

Figure 1 displays the monthly volatility risk premium of portfolios 1,10 , and 20 , as well as the market $V R P$. Note that we display the $V R P$ of the market using options 
written on the S\&P 100 Index, so that the series contained in Figure 1 is not the crosssectional average of the individual VRP. For P10VRP, P20VRP and the market, the positive peaks coincide with periods of high realized volatility. P1VRP tends to have a positive VRP even during normal economic times, while P20VRP presents a negative $V R P$ during normal and expansion months and a positive $V R P$ during bad economic times. As expected, given that the VRP beta of P20VRP over the sample period is as high as 3.89 , its behavior closely follows the market $V R P$, but with more extreme peaks.

\section{Descriptive Statistics for Return and Volatility Risk Premia Portfolios}

Table 1 contains the basic characteristics of our $40 \mathrm{VRP}$ beta-sorted equity return and volatility portfolios from January 1996 to February 2011. The four columns of Panel A report the descriptive statistics of the volatility risk premia of the $20 \mathrm{VRP}$ beta-sorted portfolios, while the four columns of Panel B contain the descriptive statistics of the returns of $20 \mathrm{VRP}$ beta-sorted portfolios. All these figures are given in annualized terms. From the first column of Panel A, we note that the average VRP values for the two extreme portfolios are $10.3 \%$ and $-3.4 \%$, respectively. By looking at the first column of Panel B, it seems that investors are willing to pay a high volatility swap rate precisely for those portfolios with extremely bad average returns. The average behavior of portfolios 19 and 20 both in terms of returns (P19ER and P20ER) and volatility swap payoffs (P19VRP and P20VRP), is surprisingly poor. The precise opposite behavior is found for portfolios P1VRP and P1ER. Overall, the lower the average portfolio return, the more negative is the average volatility risk premium. As expected, given the wellknown evidence provided, among others, by Carr and Wu (2009), market VRP is, on average, negative and equal to $-1.4 \%$. The magnitude of the cross-sectional differences in terms of returns and $V R P$ is large and seems to justify study of their determinants. 
The $V R P$ averages indicate that investors may have very different volatility investment vehicles depending on whether they go long or short on volatility. We tend to identify the purchase of volatility as a hedging instrument against potentially large stock market declines. The evidence reported in Table 1 suggests that, on average, going long on volatility can also lead to substantial gains, depending on the portfolio for which investors buy volatility.

The second column of Panel A shows that the standard deviations of the VRP values of these portfolios suggest that portfolios with a more negative average $V R P$ are the most volatile portfolios in terms of $V R P$ payoffs. As pointed out above, Figure 1 also reflects the highly volatile behavior of the VRP of P20VRP, followed by the relatively smooth behavior of P1VRP. On the other hand, the first column of Panel B shows that average returns range from an impressive $30.4 \%$ for P1ER to $-8.5 \%$ for P20ER. The second column of Panel B reports that the return volatility of the sample portfolios follows a U-shaped pattern across the 20 portfolios. Both, P1ER and P20ER have the highest return volatility across all portfolios.

The third column of Panel A of Table 1 contains the VRP betas of each of the portfolios relative to the $V R P$ of the market index. Using monthly data, we estimate a market model type of ordinary least squares (OLS) regression of the following form:

$$
V R P_{t, t+\tau}^{p}=a+\beta V R P_{t, t+\tau}^{m}+\varepsilon_{t, t+\tau}
$$

where $V R P_{t, t+\tau}^{p}$ is the volatility risk premium of each of the 20 portfolios, and $V R P_{t, t+\tau}^{m}$ is the volatility risk premium of the market index from January 1996 to February 2011. The VRP betas reflect the construction criterion, with unconditional VRP betas of -0.95 for P1VRP and 3.89 for P20VRP. As in the case of average returns 
and volatility risk premia, the cross-sectional differences in VRP betas are large. ${ }^{7}$ In the third and fourth columns of Panel B of Table 1, we also display the market return betas of the 20 portfolios with respect to the US market portfolio index and the S\&P 100 Index. As with standard deviation, the cross-sectional behavior of market betas presents a U-shaped pattern, with market betas especially high for portfolios with a more negative average $V R P$. P20ER has the highest return beta, with a value as high as 1.52 when measured relative to the S\&P 100 Index return.

Finally, the fourth column of Panel A shows the average relative bid-ask spread of the options associated with the components of the 20 portfolios. The options traded on the components of portfolios with positive and high average $V R P$ values may be extremely illiquid. If this is the case, the replicating strategy employed to obtain synthetic variance swaps associated with illiquid options may be more costly than in other cases. However, the average bid-ask spreads reflect precisely the opposite situation. P1VRP contains, on average, the most liquid options, while P20VRP presents the highest relative bid-ask spread across the 20 portfolios. Therefore, on average, market return betas and bid-ask spreads are higher for the two portfolios with the highest $V R P$ betas.

To better understand the behavior of the 20 stock return portfolios, Table 2 reports the factor loadings of seven representative portfolios (the three extreme portfolios on each side and the intermediate portfolio) on well known factor risks. Panel A of Table 2 contains the factor exposure with respect to the FF three-factor model extended with the $M O M$ and $Q M J$ factors. P1ER, the portfolio return with the most

\footnotetext{
${ }^{7}$ Bali and Hovakimian (2009) report a significantly negative relation between the variance risk premium of individual stocks and future stock returns. We use a similar measure of variance (volatility) risk premium but we estimate VRP betas from regressions of the VRP of individual stocks on the market volatility risk premium. In addition, Bali and Engle (2010) find a significantly negative relation between the time-varying conditional measures of the market volatility beta and one-month-ahead portfolio return where they estimate the time-varying conditional covariance between changes in option implied market volatility and the excess returns on equity portfolios.
} 
negative $V R P$ beta, seems to have no significant factor exposure except for the market factor. P18ER through P20ER, the portfolios with the highest $V R P$ beta, have negative $S M B$ loadings suggesting that they are large firms. Moreover, they have negative $Q M J$ loadings, which indicate that they are not only large, but also low-quality companies. On the contrary, P2ER through P10ER have positive and significant $Q M J$ betas suggesting high-quality stocks. P3ER and P10ER load positive and significant on the $H M L$ factor. Finally, most of the portfolios have negative and significant $M O M$ betas representing low momentum firms. Panel B of Table 2 reports similar evidence with respect to the FF five-factor model. As above, P18ER through P20ER are large companies, and they are firms with low profitability, since they have negative and significant betas relative to the $R M W$ factor. This is consistent with the evidence reported in Panel A. None of the portfolios have significant loadings on $H M L$, and only the extreme P20ER has a significant negative $C M A$ beta, which suggests that they are large, low profitability, low quality, and aggressive (from the investment point of view) firms. Note that these are companies with the most negative volatility risk premia.

Given the patterns reported in Table 1 for both average returns and average $V R P$ across portfolios, and the factor loadings of Table 2, we provide additional evidence following the traditional literature on long-short equity portfolios. Table 3 reports estimated return alphas for representative volatility risk premium beta-sorted portfolios for some of the aggregate risk factors employed in Table 2. These portfolios are selected from the 20 return portfolios sorted by $V R P$ betas. Portfolios with low (negative) VRP beta tend to have positive alphas, and portfolios with high $V R P$ beta present negative and statistically significant alphas, independently of the asset pricing model employed in the OLS regressions. When we form a long-short portfolio given by the difference between the returns of the low VRP beta stocks and the returns of the high VRP beta 
assets, we always find positive and statistically significant alphas. ${ }^{8}$ We conclude that stocks with low (negative) VRP beta outperform the replicating portfolio of well known factor risks and, on the contrary, stocks with high $V R P$ beta assets underperform both traditional and recent factor models. Both legs of the long-short portfolio seem to contribute significantly to performance. The $V R P$ beta premium of $2.2 \%$ per month, even with respect to the five-factor FF model extended with the momentum factor, is an impressive performance. Note that Herskovic, Kelly, Lustig, and Van Nieuwerburgh (2016) classify stocks according to exposure with respect to their common idiosyncratic volatility $(C I V)$ factor. These authors show that the top $C I V$-beta quintile earns a significantly lower average return than stocks in the bottom quintile. Their results cannot be explained by the usual aggregate risk factors. As in their case regarding the $C I V$ factor, our results suggest that the risk premium of the market volatility risk premium beta is negative in the cross-section. Moreover, given the results shown in Table 2, we know that these are large, low-quality (and low-profitability), and aggressive stocks. The simultaneous cross-sectional determinants of both equity and volatility (and variance) risk premia are analyzed in Section 6 below.

\section{The Joint Cross-Sectional Variation of Return and Volatility (Variance) Risk Premia}

In this section, we employ the rigorous econometric methodology of KRS (2013), who derive the asymptotic distribution of the cross-sectional regression $R^{2}$ as a measure of model ability to price the cross-section of average returns. Moreover, they provide standard errors of risk premium estimators adjusted for the errors-in-variable and model

\footnotetext{
${ }^{8} \mathrm{We}$ also repeat the exercise using 10 equally weighted $V R P$ beta-sorted portfolios. The results are very similar to the ones reported in Table 3. If anything, the evidence is even stronger when we employ 10 portfolios rather than 20 .
} 
misspecification. We next test the competing specifications given by the pricing models embedded in expressions (4) and (5), and the risk factors proposed in Section 2. Therefore, we now test the linear versions of the models for alternative $K$-factor beta specifications in which the return and volatility risk premia of the 40 portfolios are linear on the $K$-factor betas. ${ }^{9}$

\subsection{The Joint Cross-Sectional Results Using Classic Risk Factors}

Table 4 shows the results of the joint two-pass cross-sectional regressions using, simultaneously, return and volatility risk premia, and selected factor-based models. The general specification is given by ${ }^{10}$

$$
\begin{aligned}
E\left(\operatorname{RVRP}_{t, t+1}^{p}\right)= & \lambda_{0}+\lambda_{\text {exm }} \beta_{\text {exm }}^{p}+\lambda_{\text {smb }} \beta_{\text {smb }}^{p}+\lambda_{\text {hml }} \beta_{h m l}^{p}+\lambda_{\text {mom }} \beta_{m o m}^{p} \\
& +\lambda_{p s} \beta_{p s}^{p}+\lambda_{b a b} \beta_{b a b}^{p}+\lambda_{m v r p} \beta_{m v r p}^{p}+\lambda_{\text {def }} \beta_{\text {def }}^{p}
\end{aligned}
$$

Therefore, we begin the cross-sectional analysis using the FF three-factor model, extended with the MOM factor, the Pastor and Stambaugh (2003) market-wide liquidity, and the funding liquidity factor given by the $B A B$ portfolio of Frazzini and Pedersen (2014). ${ }^{11}$ We also recognize the market volatility risk premium, and the default spread as potentially relevant factors. In all cases, we adapt the testing framework of KRS

\footnotetext{
${ }^{9}$ The details of the KRS (2013) econometric methodology applied to this context, and the corresponding expressions for the asymptotic test of $R^{2}=0$, and the standard errors of the risk premia adjusted by errors-in-variable and model misspecification, can be found in González-Urteaga and Rubio (2016).

${ }^{10}$ Given the availability of data, we recognize that we employ a limited number of stocks and a very short (and probably unusual) sample period. Therefore, before running the main cross-sectional regressions of the paper, we perform general asset pricing cross-sectional tests to understand the peculiarities of our sample, which may also clarify the choice of risk factors. We employ either 30 or 40 test assets, and seven risk factors, including the FF factors, and the $M O M$ and $Q M J$ factors. The estimated $\hat{R}^{2 \prime} s$ range from $7.3 \%$ to $21.0 \%$. The highest $\hat{R}^{2}$ is obtained when we use the FF five-factor model expanded with the $M O M$ factor. In all specifications, we reject the null hypothesis of $R^{2}=0$. The results are available upon request.

${ }^{11}$ To check the low-beta high-beta anomaly within our sample period, we construct the $B A B$ factor using the security components of the VRP beta-sorted portfolios from January 1996 to February 2011. It turns out that the alpha of the $B A B$ portfolio is systematically positive and significantly different from zero with respect to the CAPM, the Fama-French model, the three-factor model extended with the MOM factor, and this four-factor model augmented with the market-wide liquidity of Pastor and Stambaugh (2003).
} 
(2013) to the Fama-MacBeth (1973) two-pass, cross-sectional methodology, where we estimate rolling betas using the first 60 months of the sample as a fixed estimation period, then use a rolling window of 59 months of past data plus the month in which we perform the cross-sectional regression with alternative test assets. Hence, for each month $t$, we always employ a beta estimated with 60 observations. Moreover, below all risk premium estimators, we report the $p$-values associated with the traditional FamaMacBeth standard error in parentheses and in brackets, the $p$-values of the standard error adjusted for errors-in-variable and the potential misspecification of the model. We provide two measures of goodness of fit. We report the mean absolute pricing error (MAE) across all portfolios, and the $\hat{R}^{2}$ statistic suggested by KRS (2013) with the standard error of $\hat{R}^{2}$ under the assumption that $0 \leq R^{2} \leq 1$ and, in brackets, the $p$-value for the test of the null hypothesis given by $R^{2}=0$.

The empirical results in Table 4 show a very clear pattern. The crosssectional $\hat{R}^{2} s$ for the six first models, which employ alternative combinations of traditional pricing factors together with market and funding aggregate liquidity factors, present high standard errors. In fact, we cannot reject that any of the $\hat{R}^{2} s$ of these six models is statistically equal to zero. In addition, once we adjust the Fama-MacBeth standard errors for errors-in-variable and model misspecification, we cannot reject that any of the estimated risk premia is statistically equal to zero. Using a $10 \%$ hurdle confidence level, the only exception is the beta associated with the market volatility risk premium. This is consistent with the evidence of Bali and Zhou (2016) for equities and González-Urteaga and Rubio (2016) for volatility risk premia. In the two cases in which 
we employ the FF factors and the momentum factor, the risk premium of the market volatility risk premium is, as expected, negative and has $p$-values below $0.10{ }^{12}$

The empirical evidence changes completely once we introduce the default premium as a pricing factor. In all nine specifications, we always reject the hypothesis that the cross-sectional $\hat{R}^{2} s$ are zero. The $p$-values range from 0.000 to 0.023 depending upon the specification employed in the cross-section. As shown by González-Urteaga and Rubio (2016) for volatility risk premia, and Petkova (2006) and KRS (2013) for equities, the default premium seems to be a key factor in explaining the cross-section of return and volatility risk premia simultaneously. It is also the case that Bali (2008) shows a significantly positive relation between the time-varying conditional measure of default beta and one-month-ahead portfolio returns of 30-industry and 25-size-book-tomarket equity portfolios. Indeed, the estimated risk premia associated with the default premium beta is always positive and statistically different from zero even when we adjust for errors-in-variable and model misspecification. Moreover, it turns out that none of the risk premia related to the market portfolio return, the FF factors, or the momentum or liquidity factors are statistically different from zero. As before, the relevant exception is the market volatility risk premium beta. In three out of the nine models with the default premium beta as an explanatory variable, the risk premia of the market volatility risk premium beta is negative and statistically different from zero at the $5 \%$ level, and in seven cases it is significantly different from zero at the $10 \%$ level. These results suggest that a two-factor model with the default premium and the market

\footnotetext{
${ }^{12}$ The negative sign reflects the fact that the market volatility risk premium tends to be positive in events of high marginal utility. The negative risk premium associated with the market volatility risk premium is consistent with the results reported by Bali and Hovokimian (2009), and Bali and Zhou (2016). The apparent difference is due simply to the definition of the variance risk premium used in these papers. We define the variance risk premium as the difference between the expected value of the realized variance under the physical measure $P$ and the risk-neutral measure $Q$, whereas the other authors define the variance risk premium in exactly the opposite way, as the expected value under $Q$ minus $P$.
} 
volatility risk premium as factors explains reasonably well the simultaneous crosssection of return and volatility risk premia. Also note that the cross-sectional $\hat{R}^{2} s$ across all these nine models are very similar. The highest $\hat{R}^{2}$ equals $37 \%$ when the model includes the market return beta, the $H M L$ and $M O M$ betas, and the market $V R P$ and default betas. However, none of the risk premia of these three classic factors is statistically different from zero even when we employ the traditional Fama-MacBeth standard errors. In any case, it is also true that the cross-sectional intercept is always statistically different from zero which suggests that we are missing important pieces of information from the cross-section when we simply employ the selected factors.

\subsection{The Joint Cross-Sectional Results Using the Fama-French Five-Factor Model}

Given the popularity of the FF five-factor model, we extend the previous analysis to include the comparison with the FF five-factor model. ${ }^{13}$ We report the empirical results in Table 5. For clarity of exposition, the first line of Table 5 contains the cross-sectional results using the market volatility risk premium, and the default spread already reported in Table 4. The second line reports the result for the five-factor model. The crosssectional $\hat{R}^{2}$ is 0.20 but is not statistically different from zero. It is true, however, that the market risk premium is positive and significant, and the risk premium associated with the $H M L$ factor is negative and statistically significant, even adjusting for errorsin-variable and model misspecification.

As in Table 4, the empirical results clearly change when we introduce the market volatility risk premium, and the default spread. Note that the $\hat{R}^{2}$ of the FF five-factor model seems to be lower than the 0.302 from the simple two-factor model. The results

\footnotetext{
${ }^{13}$ The FF five-factor model also presents a reasonable performance during our sample period for overall cross-sectional tests with several test assets and risk factors.
} 
reported in the third line of Table 5 clarify the previous evidence. When we extend the five-factor model with the market $V R P$ and default, the market risk premium and the $H M L$ premium remain positive and negative, respectively. However, neither is statistically different from zero. The risk premia associated with the $C M A$ and $R M W$ factors are positive and statistically significant when using the classic standard errors, although they lose significance when we employ the adjusted KRS (2013) standard errors. On the other hand, the market volatility risk premium is negative and significant, and the default premium remains strong, positive and statistically different from zero. The two-factor model continues to be a very reasonable model to explain the joint crosssectional variation of return and volatility risk premia. ${ }^{14}$

\subsection{The Joint Cross-Sectional Results Using Leverage and Direct Measures of}

\section{Funding Liquidity}

Given the new evidence reported by Adrian, Etula, and Muir (2014), Fontaine and García (2012), and Fontaine, García and Gungor (2014), we extend our previous empirical tests to include both direct funding liquidity measures and changes in the leverage broker-dealer factor. We employ two measures of funding liquidity given by the TED spread and the measure proposed by Fontaine and García (2012), respectively. ${ }^{15}$ The leverage factor is the seasonally adjusted log changes in the level of broker-dealer leverage; it is available quarterly from 1968 to 2009. Given that we employ monthly data from 1996 to 2011 , we employ the alternative measure of the leverage factor at monthly frequency also suggested by Adrian, Etula and Muir (2014).

\footnotetext{
${ }^{14}$ It is also reasonable to extend our previous analysis to individual return and volatility risk premia data. We replicate the previous analysis with 106 individual stocks that have complete data over our sample period. Although the $\hat{R}^{2}$ values are lower, and the risk premium estimates across models are also slightly lower, the qualitative overall results are exactly the same as those in Table 5.

${ }^{15}$ The TED spread is the difference between the three-month Treasury bill and LIBOR rates. The funding liquidity data are available at http://jean-sebastienfontaine.com. We thank Jean-Sebastien Fontaine for making the data available to researchers.
} 
Table 6 contains the empirical results. The first row displays again the results of the two-factor model already addressed in Table 4. Then, we report the empirical results of alternative two-factor models where we include the market $V R P$ together with the individual leverage factor or the competing funding liquidity measures. The risk premia of both the leverage factor and the TED spread are not statistically different from zero and we cannot reject that the cross-sectional $\hat{R}^{2} s$ are equal to zero. On the other hand, the risk premium of the funding liquidity measure of Fontaine and García (2012) is indeed statistically different from zero with the right economic sign. However, we cannot reject that the cross-sectional $\hat{R}^{2}$ is equal to zero.

As in Tables 4 and 5, the empirical results improve when we include the default beta risk in the cross-section. Independently of the specification employed, the crosssectional $\hat{R}^{2} s$ are statistically different from zero. When we analyze four-factor models with the market $V R P$, default, leverage factor, and funding liquidity measures, the evidence shows that the leverage factor dominates both the TED spread and the funding liquidity measure of Fontaine and García (2012). The $\hat{R}^{2}{ }^{\prime} s$ of the four-factor models are $39.1 \%$ and $38.5 \%$ for the model with the leverage factor and either the TED spread or the funding liquidity measure, respectively. The important point here is that the risk premia associated with the funding liquidity measures are not statistically significant but the leverage factor remains positive and statistically significant at least with respect to the traditional Fama-MacBeth standard error. Moreover, the $p$-value associated with the adjusted standard error is much smaller for the leverage factor than for the funding liquidity measure of Fontaine and García (2012). To conclude, when we extend the twofactor model adding simultaneously the leverage factor and funding liquidity, the results seem to be favorable to the leverage factor. In any case, once we include the default beta 
risk, none of the additional factors explains the joint cross-section of equity and volatility risk premia.

\subsection{The Cross-Sectional Analysis with Variance Risk Premia}

All our cross-sectional tests employ volatility risk premia rather than variance risk premia. The pricing equation (6) holds in the variance but not in the volatility space. As discussed by Carr and Lee $(2007,2009)$, due to the concavity's price impact associated with Jensen's inequality, the difference between the value of a variance swap and the value of a volatility swap depends on the volatility of volatility of the underlying asset. If we recognize this potential bias and adjust our estimated volatility risk premia accordingly, the dispersion between the volatility risk premia across portfolios remains. Therefore, up to now, we conduct all tests using volatility risk premia.

This issue, however, is not trivial and deserves further empirical evidence. We now test whether the two-factor model holds even in the variance space and not only in volatility space. We also test a five-factor model with the excess market return, $H M L$, $M O M$, and extended with the market variance risk premium, and the default premium.

This is the model with the highest $R^{2}$ reported in Table 4 . We finally analyze the FF five-factor model, also extended with the market variance risk premium and the default premium.

As in Carr and $\mathrm{Wu}$ (2009), we define the log variance risk premium for any asset or portfolio $a$ as,

$$
V A R R P_{t, t+\tau}^{a}=\ln \left(\frac{R V A R_{t, t+\tau}^{a}}{M F I V A R_{t, t+\tau}^{a}}\right)
$$


where $R V A R_{t, t+\tau}^{a}$ and $M F I V A R_{t, t+\tau}^{a}$ are given by expressions (8) and (6), respectively. We use our 40 portfolios of return and variance risk premia sorted by the variance risk premium betas estimated from the log variance risk premium of equation (13).

The empirical performance of the two-factor model is reported in Table 7. The results are even clearer than the reported evidence using the volatility risk premia. The market variance risk premium beta is negative and statistically significant even under the KRS (2013) standard error. The default beta is positive and significantly different from zero, and the overall fit of the model is similar to the evidence described above. In this case, the $\hat{R}^{2}$ is 0.29 and is statistically different from zero. Similar results are obtained for the other competing models. The $\hat{R}^{2}$ of the five-factor model is 0.31 which is lower than the $\hat{R}^{2}$ reported in Table 4 . However, as in Table 4, none of the risk premia is statistically different from zero except for the market variance risk premium and the default premium. In both cases, the intercept is significantly different from zero. Regarding the FF five-factor model augmented with the market variance risk premium and default, the results are also very similar to those shown in Table 5. The $\hat{R}^{2}$ reported in Table 7 is practically the same as that given in Table 5. As in all other cases, variance risk premium and the default premium are statistically different from zero. A relevant difference is that the risk premium associated with the $R M W$ factor is now estimated with higher precision. In particular, the profitability risk premium is positive but significantly different from zero even with respect to the adjusted standard errors. ${ }^{16} \mathrm{We}$ conclude that the results are robust to the use of either the volatility or the variance risk premia in the two-pass cross-sectional regressions. The potential biases due to the

\footnotetext{
${ }^{16}$ As an additional robustness check, we also test the two-factor model extended with leverage and TED using the variance risk premia rather than the volatility risk premia. The results remain practically identical with slightly lower $\hat{R}^{2}$. The performance of the market variance risk premium and the default premium remain strong. Their risk premia maintain their signs, and they are statistically different from zero.
} 
concavity's price impact when using the volatility rather than the variance risk premium do not seem to be relevant enough to modify the conclusions about the simultaneous cross-sectional pricing of returns and volatilities. In any case, the explicit comparison of the cross-sectional results using both variance and volatility risk premia is a worthwhile exercise, not previously reported in literature.

\section{Market Segmentation and Drivers of Pricing in the Return and Volatility Segments of the Market}

Does the same factor model of the SDF price the return and volatility segments of the market? Do the return portfolios add some relevant information to the pricing of VRP portfolios? These are key issues in this paper. Although both the return and volatility portfolios may contain relevant information on the pricing of risk, as the results reported in Tables 4, 5, and 6 seem to suggest, is conceivable that risk is priced statistically and economically differently in the two segments of the market.

We first repeat the cross-sectional pricing analysis for both sets of portfolios separately. The results are reported in Table 8 . We employ four representative asset pricing models to carry out the analysis: the two-factor model with the market $V R P$ and default (model 13), the five-factor model with the highest $\hat{R}^{2}$ in the simultaneous test using 40 portfolios (model 12), the FF five-factor model extended with the market VRP and default (model 17), and the two-factor model augmented with the leverage and funding liquidity factors (model 24). Panel A of Table 8 presents the evidence for the 20 $V R P$ portfolios. We already know from González-Urteaga and Rubio (2016) that the market $V R P$ and the default premium are priced in the cross-section of volatility risk

premia. This result is displayed in the first line of Panel A. The cross-sectional $\hat{R}^{2}$ is 0.514 and is statistically significant. A similar result holds when we add the FF three- 
factor model and the MOM factor. The $\hat{R}^{2}$ is slightly higher than before, but none of the other risk premia are statistically significant. The FF five-factor model presents a strong performance with the highest cross-sectional $\hat{R}^{2}$ of 0.771 . The default risk premium remains positive and significant. However, although the risk premium of the market $V R P$ remains negative and statistically different from zero relative to the classic standard errors, it losses significance when we employ the adjusted standard errors of KRS (2013). In addition, the profitability risk premium is positive and statistically significant even adjusting for errors-in-variable and model misspecification. As shown in Table 2, there are very relevant cross-sectional differences in the return loadings of both the $Q M J$ and $R M W$ factors for stocks with positive and negative average volatility risk premia. The stocks with negative average $V R P$, high volatility of $V R P$, and high $V R P$ beta are characterized as stocks with low quality and low profitability. Finally, the overall pricing of the market $V R P$, and the default premium remains significant when we add the leverage factor and $T E D$, as a proxy for funding liquidity.

Panel B of Table 8 displays the results for the 20 equity return portfolios. The $\hat{R}^{2}$ of the two-factor model is much lower than in Panel A, although it remains statistically significant, and is equal to 0.367 . The default premium is once again positive and statistically different from zero. As expected, the market VRP is now positive given that high marginal utility events are associated with low market returns and high volatility. However, the market $V R P$ is not statistically different from zero. Contrary to the volatility portfolios, this factor does not seem to be significantly priced in the crosssection of return portfolios, although it becomes estimated with more precision in the specification with leverage and funding liquidity. Finally, none of the FF factors seem to be priced in the presence of default premium. In particular, the profitability factor has a risk premium with an adjusted $p$-value of 0.82 . 
The results shown in Table 8 suggest that the return and volatility portfolios are priced differently, although the default premium is positive and strongly significant in both segments of the market. This seems reasonable since the cross-sectional differences between the return and volatility portfolios are closely related to default risk. The default return betas of portfolios with negative, on average, volatility risk premia are negative. This suggests that the components of these portfolios are negatively affected by times of financial stress or high credit spreads. At the same time, the negative volatility risk premia of these portfolios implies that investors are willing to pay a high volatility swap price to hedge against the extreme high marginal utility events associated with these portfolios. On the other hand, the return default betas of portfolios with positive volatility risk premia are positive. Thus, extreme portfolios sorted by $V R P$ betas present precisely the opposite behavior. This is closely related to the cross-sectional differences in terms of quality and profitability discussed in Section 5. Both sets of portfolios are connected through their sensitivity to financial distress.

In any case, we still must check whether the risk premia of the return and volatility portfolios reported in Table 8 are statistically different for a given factor risk. Panel A of Figure 2 shows the time-varying behavior of the risk premium for the market volatility risk premia of both the return and volatility portfolios. Panel B shows the temporal behavior of the default premium for both portfolio sets. Although the overall pattern presents similarities, particularly during high peaks, there are also differences. The relevant question is whether these risk premia are, on average, equal to each other. Table 9 reports the results from Wald tests to statistically check whether these risk premia are significantly equal across models and both sets of portfolios. Therefore, for a given pricing model and a given factor $i$, we test whether the following null hypothesis across both sets of return and volatility portfolios is satisfied: 


$$
\lambda_{i}^{20 V O L}=\lambda_{i}^{20 E Q U}
$$

We employ the same four pricing models used in Table 8. The first line of Table 9 shows that we reject the null hypothesis that the risk premia of the two-factor model are equal across both sets of portfolios. This holds for the default premium but also for the market $V R P .{ }^{17}$ A similar result holds for the five-factor model of the second line of Table 9, and for the model with leverage and funding liquidity of the fourth line. The only exception is the FF five-factor model in which the default and market volatility risk premia are not statistically different across the return and volatility portfolios. The $p$-value for the null hypothesis of equal default risk premia for returns and volatilities is 0.25 . Interestingly, the risk premium associated with the profitability $R M W$ factor is significantly different in both portfolio sets.

Panels A and B of Figure 3 display the kernel estimated density functions of the market volatility and default Fama-MacBeth estimated risk premia for both the return and volatility portfolios. ${ }^{18}$ For the market $V R P$ we observe not only the reported difference in the mean, with a high peak around the mean for the volatility portfolios, but we also find that both tails are fatter in the case of the return portfolios. However, the opposite finding is shown in the case of the default risk premium. The volatility portfolios present fatter tails than the return portfolios, and the density of the volatility portfolios is positively skewed. The fatter tails are consistent with the time-varying behavior of the default risk premium displayed in Panel B of Figure 2. In most cases, the positive and negative peaks are more pronounced in the volatility portfolios relative to the peaks in the return portfolios.

\footnotetext{
${ }^{17}$ The Wald tests use the adjusted standard errors of KRS (2013). Therefore, these tests control for errorsin-variables and model misspecification.

${ }^{18}$ These risk premia are estimated using the two-factor model.
} 
Despite the fact that default risk is positive and significantly priced in both the return and volatility portfolios, we tend to reject that both risk premia are equal. The evidence of different default risk premia for both sets of portfolios is not necessarily surprising. Our volatility risk premium measures are obtained from options quotes. It is well known that demand-pressure effects help explaining the relative expensiveness of individual and index options. As shown by Garleanu, Pedersen, and Poteshman (2009), local demand and supply factors are relevant for options markets, while they may not be as important for stock markets. In addition, Adrian and Song Shin (2010) show that dealers actively changes their balance sheets, increasing leverage in good times and decreasing it in bad economic times. It turns out that these balance sheet changes forecast primarily changes in the market $V R P$. This may complement the demand-based arguments of Garleanu, Pedersen, and Poteshman (2009), because these financial intermediaries may be net suppliers of options to hedgers who are positioned on the demand side of the market. These local options effects may easily introduce differences in both segments of the market which may explain why we tend to reject that the consistently significant default risk premia are equal in the return and volatility markets. Indeed, Barras and Malkhozov (2016) test whether the conditional market variance risk premium measured in the equity and option markets are equal. Their empirical evidence formally rejects the null hypothesis that the two variance risk premia are equal. The differences are attributed to market frictions, and are consistent with the role of financial intermediaries in the option market.

As our final analysis, we study whether the common factors explaining the simultaneous data of the 40 return and volatility portfolios also explain both sets of portfolios separately. This is basically a test of integration of both segments of the market. We follow the proposal of Pukthuanthong and Roll (2009) who argue that 
correlations are likely to be poor measures of integration, and propose an alternative measure based on the explanatory power of a multi-factor model.

We have 40 portfolios of volatility risk premia and equity returns with both daily and monthly data. For each year from 1996 to 2010, we compute the variancecovariance matrix of the $V R P$ and equity returns using daily data. We calculate the eigenvectors, which are sorted from largest to smallest eigenvalue. Then, we estimate principal components from the data of $V R P$ and equity returns in the subsequent year. As an example, the eigenvectors calculated from the 1996 variance-covariance matrix are applied to the 40 portfolios during 1997 . We repeat this procedure for every year through 2011. This generates 15 years of out-of-sample principal components.

In each year, we employ seven principal components, which account for from $85.2 \%$ to $98.7 \%$ of the total variability of the variance-covariance matrix. ${ }^{19}$ We impose these principal components as the proxies for common factors in the 40 portfolios of returns and volatilities. These estimated common factors are the explanatory variables of a series of regressions, one for each available portfolio of either $V R P$ or returns in each year from 1997 to 2011 . We run these 40 regressions with daily data, and we estimate the adjusted $R$-square of each regression and, therefore, for each of the 40 portfolios. In each year, we take the average of these $R$-squares across the $20 V R P$ portfolios and the average of the $R$-squares across the 20 return portfolios. The adjusted average $R$-squares from these regressions are our measure of integration across the return and volatility segments of the market.

We report the results in Panel A of Table 10. The first column shows the estimated $R$-squares on a yearly basis for the $20 V R P$ portfolios. Similarly, the second column displays the yearly estimated $R$-squares for the 20 return portfolios. Panel A of Figure 4

\footnotetext{
${ }^{19} \mathrm{We}$ also tried from four to nine principal components. The results remain very similar in all cases.
} 
shows the pattern of these $R$-squares for both sets of portfolios. There is an upward trend in the integration of the two segments that seems to be related to the Great Recession. This finding deserves a word of caution. As pointed out by Bekaert, Harvey, and $\mathrm{Ng}$ (2005), in the framework of contagion, the increasing correlation during bad economic times may due to the higher volatility of common factors, which suggests that the $R$-square from a multi-factor model may not be an appropriate measure of integration. As a measure of contagion, they propose the correlation of the factor model residuals. On the other hand, as argued by Pukthuanthong and Roll (2009), sampling error in residual volatility may be more problematic than sampling variation in the common factors. Our point is that integration between the two segments of the market may be time-varying and that integration seems to increase during stressed economic times.

On average, common factors explain $90.3 \%$ of the variability of the $V R P$ of volatility portfolios, and only $64.8 \%$ of the variability of the return portfolios. Moreover, during the years with NBER official recession months (2001, 2008, and 2009), the average $R$-squares are $93.1 \%$ and $71.7 \%$ for volatility and return portfolios, respectively. Common factors better explain the behavior of the volatility portfolios. This is consistent with the cross-sectional $\hat{R}^{2}$ 's of the two-factor model, and the FF five-factor model extended with market $V R P$ and the default premium, reported in Table 8. The $\hat{R}^{2}$ 's are 0.514 and 0.771 for the two-factor and augmented FF five-factor model, respectively, for the volatility portfolios, but only 0.367 and 0.678 for the return portfolios.

One additional issue deserves special discussion. We must recognize that both the return and volatility risk premium portfolios sort assets by the $V R P$ betas rather than by stock market betas. We next perform the reverse exercise. Specifically, we create 40 
return and volatility risk premium portfolios on market betas. This may be potentially relevant given the strong return spreads delivered by the volatility beta ranking. We repeat the integration test of Pukthuanthong and Roll (2009) using the new 40 portfolios. Panel B of Table 10, and Panel B of Figure 4 contain the results regarding the $\hat{R}^{2}$ 's for both sets of portfolios during each year of the sample period. On average, common factors explain $82.2 \%$ of the variability of the $V R P$ of volatility portfolios, and only $58.5 \%$ of the variability of the return portfolios. Moreover, during the years with recession months, the average $R$-squares are $88.4 \%$ and $64.3 \%$ for volatility and return portfolios, respectively. We conclude that, independently of the sorting procedure, common factors better explain the behavior of the volatility portfolios. ${ }^{20}$

\section{Conclusions}

The cross-section of equity returns has been extensively analyzed over the past four decades. This literature includes market-wide volatility risk as an additional factor. In addition, the cross-sectional variability of the volatility risk premia is recently studied by González-Urteaga and Rubio (2016). However, joint cross-sectional variation of return and volatility risk premia has been ignored. We argue that both equity returns and volatilities may be jointly determined at the cross-section. This would be especially so if these two segments are integrated. Hence, this paper estimates simultaneously the crosssectional variation of 40 portfolios using both volatility and return risk premia as test portfolios. To construct these portfolios, we first rank individual VRP values by their

\footnotetext{
${ }^{20}$ A related important issue is whether the two-factor model with the market $V R P$ and default still price the 40 portfolios sorted by stock market betas. The two-pass cross-sectional tests of the two-factor model using the 40 portfolios sorted by market betas show that the estimated risk premium associated with the default beta is positive and highly significant. Indeed, the risk premium coefficient is 0.011 , which is higher than the estimated coefficient reported in Table 4. On the other hand, the estimated risk premium of the market VRP remains negative but is not statistically different from zero. The estimated $\hat{R}^{2}$ is $40.2 \%$, which is higher than in Table 4 and it remains statistically different from zero. Similar results are obtained using the extended FF five-factor model.
} 
betas with respect to the market volatility risk premium. Then, we form $20 \mathrm{VRP}$ betasorted portfolios. Simultaneously, using the underlying components of these 20 portfolios, we construct another 20 equity return portfolios. We use these 40 portfolios as test assets in the empirical application.

We show that beta with respect to market volatility risk premia and the default premium beta have statistically significant risk premia that help explain the joint crosssectional variation of average return and volatility risk premia. The cross-sectional $\hat{R}^{2}$ of the two-factor model is $30.2 \%$ and is statistically different from zero. The default premium factor, whose estimated risk premium related to the default premium beta, is as high as $7.2 \%$ on annual basis, seems to be the key factor in explaining the crosssection. These empirical results hold even if we allow for potential misspecification of the models. It is important to note that González-Urteaga and Rubio (2016) show that the success of the default premium in the cross-sectional variation of the volatility risk premia can be explained by the very different behavior that the underlying components of the $20 V R P$ beta-sorted portfolios have with respect to financial stress risk. This may also explain the results for the simultaneous cross-section of equity and volatility risk premia. These results are robust to the FF five-factor model, pricing models with leverage and funding liquidity, the use of individual assets instead of portfolios, and to variance risk premia estimates.

Finally, and more importantly, we employ different strategies to test the integration of the return and volatility segments of the market. We repeat our empirical tests separately with the return and volatility portfolios. Despite the fact that the default premium is positive and significantly priced in both segments, we tend to reject the null hypothesis that the risk premia associated with the market $V R P$, and the default premium are equal across both sets of portfolios. Moreover, the risk premium of the 
profitability factor is positive and significantly priced in the cross-section of volatility risk premia, but not in the cross-section of equity returns. Indeed, common factors explain on average $90 \%$ of the variability of volatility portfolios, but only $65 \%$ of the variability of equity portfolio returns. It is also true that the common factors seem to explain a higher proportion of the behavior of both sets of portfolios during the final years of the sample, which partially coincide with years of financial crisis. These results hold even if we rank assets on market betas rather than on VRP betas. 


\section{References}

Acharya, V., and L. Pedersen (2005), Asset Pricing with Liquidity Risk, Journal of Financial Economics 77, 374-410.

Adrian, T., and H. Song Shin (2010), Liquidity and Leverage, Journal of Financial Intermediation 19, 418-437.

Adrian, T., E. Etula, and T. Muir (2014), Financial Intermediaries and the Cross-Section of Asset Returns, Journal of Finance 69, 2557-2596.

Amihud, Y., A. Hameed, W. Kang, and H. Zhang (2015), The Illiquidity Premium: International Evidence, Journal of Financial Economics 117, 350-368.

Ang, A., R- Hodrick, Y. Xing, and X. Zhang (2006), The Cross-Section of Volatility and Expected Returns, Journal of Finance 61, 259-299.

Asness, C., A. Frazzini, and L. Pedersen (2014), Quality Minus Junk, Working Paper, AQR Capital Management and New York University, Stern School of Business.

Bakshi, G., C. Cao, and Z. Chen (1997), Empirical Performance of Alternative Option Pricing Models, Journal of Finance 52, 2003-2049.

Bali, T. (2008), The Intertemporal Relation between Expected Returns and Risk, Journal of Financial Economics 87, 101-131.

Bali, T., and R. Engle (2010), The Intertemporal Capital Asset Pricing Model with Dynamic Conditional Correlations, Journal of Monetary Economics 57, 377-390.

Bali, T., and A. Hovakimian (2009), Volatility Spreads and Expected Stock Returns, Management Science 55, 1797-1812.

Bali, T., and H. Zhou (2016), Risk, Uncertainty, and Expected Returns, Journal of Financial and Quantitative Analysis 51, 707-735.

Barras, L., and A. Malkhozov (2016), Does Variance Risk Have Two Prices? Evidence from the Equity and Option Markets, Journal of Financial Economics 121, 79-92. 
Bekaert, G., C. Harvey, and A. Ng (2005), Market Integration and Contagion, Journal of Business 78, 39-69.

Bekaert, G., R. Hodrick, and X. Zhang (2012), Aggregate Idiosyncratic Volatility, Journal of Financial and Quantitative Analysis 47, 1155-1185.

Bekaert, G., and M. Hoerova (2014), The VIX, the Variance Premium and Stock Market Volatility, Journal of Econometrics 183, 181-192.

Britten-Jones, M., and A. Neuberger (2002), Option Prices, Implied Price Processes, and Stochastic Volatility, Journal of Finance 55, 839-866.

Bollerslev, T., Tauchen, G., Zhou, H., 2009, Expected Stock Returns and Variance Risk Premia, Review of Financial Studies 22, 4463-4492.

Brunnermeier, M. and L. Pedersen (2009), Market Liquidity and Funding Liquidity, Review of Financial Studies 22, 2201-2238.

Campbell, J., S. Giglio, C. Polk, and R. Turley (2014), An Intertemporal CAPM with Stochastic Volatility, Working Paper, Harvard University.

Cao, C., F. Yu, and Z. Zhong (2010), The Information Content of Option-Implied Volatility for Credit Default Swap Valuation, Journal of Financial Markets 13, 321343.

Carhart, M. (1997), On Persistence in Mutual Fund Performance, Journal of Finance $52,57-82$.

Carr, P. and R. Lee (2007), Realized Volatility and Variance: Options via Swaps, Risk $5,76-83$.

Carr, P. and R. Lee (2009), Volatility Derivatives, Annual Review of Financial Economics 1, 1-21.

Carr, P., and L. Wu (2009), Variance Risk Premia, Review of Financial Studies 22, 1311-1341. 
Driessen, J., P. Maenhout, and G. Vilkov (2009), The Price of Correlation Risk: Evidence from Equity Options, Journal of Finance 64, 1377-1406.

Duarte, J., A. Kamara, S. Siegel, and C. Sun (2014), The Systematic Risk of Idiosyncratic Volatility, SSRN, http://dx.doi.org/10.2139/ssrn.1905731.

Fama, E., and J. MacBeth (1973), Risk, Return and Equilibrium: Empirical Tests, Journal of Political Economy 81, 607-636.

Fama, E., and K. French (1993), Common Risk Factors in the Returns on Stocks and Bonds, Journal of Financial Economics 33, 3-56.

Fama, E., and K. French (2014), Dissecting Anomalies with a Five-Factor Model, Working Paper, Booth School of Business, University of Chicago and Amos Tuck School of Business, Dartmouth College.

Fama, E., and K. French (2015), A Five-Factor Asset Pricing Model, Journal of Financial Economics 116, 1-22.

Fontaine, J-S., and R. García (2012), Bond Liquidity Premia, Review of Financial Studies 25, 1207-1254.

Fontaine, J-S., R. García, and S. Gungor (2014), Funding Liquidity Risk and the CrossSection of Stock Returns, Working Paper, Bank of Canada.

Frazzini, A., and L. Pedersen (2014), Betting against Beta, Journal of Financial Economics 111, 1-25.

Garleanu, N., L. Pedersen, and A. Poteshman (2009), Demand-Based Option Pricing, Review of Financial Studies 22, 4259-4299.

Garleanu, N., and L. Pedersen (2011), Margin-Based Asset Pricing and Deviations from the Law of One Price, Review of Financial Studies 24, 1980-2022.

González-Urteaga, A., and G. Rubio (2016), The Cross-Sectional Variation of Volatility Risk Premia, Journal of Financial Economics 119, 353-370. 
Herskovic, B., B. Kelly, H. Lustig, and S. Van Nieuwerburgh (2016), The Common Factor in Idiosyncratic Volatility: Quantitative Asset Pricing Implications, Journal of Financial Economics 119, 249-283.

Jiang, G., and Y. Tian (2005), The Model Free Implied Volatility and its Information Content, Review of Financial Studies 18, 1305-1342.

Kan, R., C. Robotti, and J. Shanken (2013), Pricing Model Performance and the TwoPass Cross-Sectional Regression Methodology, Journal of Finance 68, 2617-2649.

Maio, P., and P. Santa-Clara (2012), Multifactor Models and their Consistency with the ICAPM, Journal of Financial Economics 196, 586-613.

Martin, I. (2013), Simple Variance Swaps, NBER Working Paper 16884.

Novy-Marx, R. (2013), The Other Side of Value: The Gross Profitability Premium, Journal of Financial Economics 108, 1-28.

Pastor, L., and R. Stambaugh (2003), Liquidity Risk and Expected Stock Returns. Journal of Political Economy 111, 642-685.

Petkova, R. (2006), Do the Fama-French Factors Proxy for Innovations in Predictive Variables? Journal of Finance 61, 581-612.

Pukthuanthong, K., and R. Roll (2009), Global Market Integration: A Better Way to Measure it and its Applications, Journal of Financial Economics 94, 214-232.

Wang, H., Y. Zhou, and H. Zhou (2013), Credit Default Swap Spreads and Variance Risk Premia, Journal of Banking and Finance 37, 3733-3746.

Zhou, H. (2010), Variance Risk Premia, Asset Predictability Puzzles, and Macroeconomic Uncertainty, Working Paper, Federal Reserve Board. 
Table 1

Descriptive Statistics of Volatility Risk Premia and Equity Returns for 20 Portfolios Sorted by the Volatility Risk Premium Betas: January 1996 to February 2011

\begin{tabular}{|c|c|c|c|c|c|c|c|c|c|}
\hline \multicolumn{5}{|c|}{$\begin{array}{l}\text { Panel A: Descriptive Statistics of the Volatility Risk Premia of } 20 \\
\text { Portfolios Sorted by Volatility Risk Premium Beta }\end{array}$} & \multicolumn{5}{|c|}{$\begin{array}{c}\text { Panel B: Descriptive Statistics of the Returns of } 20 \text { Portfolios Sorted } \\
\text { by Volatility Risk Premium Beta }\end{array}$} \\
\hline $\begin{array}{c}\text { Volatility } \\
\text { Risk } \\
\text { Premia } \\
\end{array}$ & $\begin{array}{l}\text { Average } \\
\text { VRP }\end{array}$ & $\begin{array}{l}\text { Volatility } \\
\text { of VRP }\end{array}$ & $\begin{array}{l}\text { VRP Beta } \\
(\mathrm{S} \& \mathrm{P} 100)\end{array}$ & $\begin{array}{c}\text { Relative } \\
\text { Bid-Ask } \\
\text { Spread }\end{array}$ & $\begin{array}{l}\text { Equity } \\
\text { Returns }\end{array}$ & $\begin{array}{l}\text { Average } \\
\text { Return }\end{array}$ & $\begin{array}{c}\text { Return } \\
\text { Volatility }\end{array}$ & $\begin{array}{c}\text { Market } \\
\text { Beta (US } \\
\text { Market) }\end{array}$ & $\begin{array}{c}\text { Market } \\
\text { Beta } \\
(\mathrm{S} \& \mathrm{P} 100)\end{array}$ \\
\hline P1VRP & 0.103 & 0.179 & -0.946 & 0.257 & P1ER & 0.304 & 0.379 & 1.164 & 1.168 \\
\hline P2VRP & 0.040 & 0.092 & -0.229 & 0.256 & P2ER & 0.241 & 0.251 & 1.042 & 1.050 \\
\hline P3VRP & 0.024 & 0.082 & 0.056 & 0.259 & P3ER & 0.274 & 0.241 & 0.893 & 0.922 \\
\hline P4VRP & 0.018 & 0.072 & 0.223 & 0.265 & P4ER & 0.219 & 0.228 & 1.017 & 1.008 \\
\hline P5VRP & 0.009 & 0.066 & 0.307 & 0.260 & P5ER & 0.247 & 0.193 & 0.758 & 0.771 \\
\hline P6VRP & 0.001 & 0.062 & 0.368 & 0.270 & P6ER & 0.254 & 0.206 & 0.890 & 0.897 \\
\hline P7VRP & -0.0002 & 0.067 & 0.511 & 0.268 & P7ER & 0.203 & 0.199 & 0.884 & 0.918 \\
\hline P8VRP & -0.004 & 0.067 & 0.558 & 0.261 & P8ER & 0.191 & 0.214 & 0.964 & 0.987 \\
\hline P9VRP & -0.010 & 0.069 & 0.704 & 0.270 & P9ER & 0.233 & 0.196 & 0.850 & 0.851 \\
\hline P10VRP & -0.010 & 0.077 & 0.819 & 0.273 & P10ER & 0.149 & 0.199 & 0.931 & 0.977 \\
\hline P11VRP & -0.019 & 0.079 & 0.919 & 0.269 & P11ER & 0.187 & 0.198 & 0.867 & 0.868 \\
\hline P12VRP & -0.021 & 0.086 & 1.011 & 0.281 & P12ER & 0.163 & 0.211 & 0.949 & 0.958 \\
\hline P13VRP & -0.026 & 0.088 & 1.009 & 0.275 & P13ER & 0.143 & 0.190 & 0.823 & 0.874 \\
\hline P14VRP & -0.022 & 0.099 & 1.219 & 0.279 & P14ER & 0.115 & 0.209 & 0.972 & 1.013 \\
\hline P15VRP & -0.028 & 0.106 & 1.327 & 0.278 & P15ER & 0.100 & 0.209 & 1.012 & 1.020 \\
\hline P16VRP & -0.031 & 0.119 & 1.444 & 0.277 & P16ER & 0.105 & 0.202 & 0.873 & 0.935 \\
\hline P17VRP & -0.029 & 0.139 & 1.782 & 0.283 & P17ER & 0.125 & 0.237 & 1.138 & 1.142 \\
\hline P18VRP & -0.029 & 0.165 & 2.068 & 0.281 & P18ER & 0.052 & 0.245 & 1.163 & 1.164 \\
\hline P19VRP & -0.035 & 0.192 & 2.420 & 0.286 & P19ER & 0.012 & 0.254 & 1.233 & 1.241 \\
\hline P20VRP & -0.034 & 0.312 & 3.891 & 0.296 & P20ER & -0.085 & 0.321 & 1.463 & 1.521 \\
\hline $\begin{array}{l}\text { Overall } \\
\text { Market }\end{array}$ & -0.014 & 0.069 & 1.000 & - & $\begin{array}{l}\text { Overall } \\
\text { Market }\end{array}$ & 0.068 & 0.165 & 0.929 & 1.000 \\
\hline
\end{tabular}

The volatility risk premium (VRP) for each portfolio is defined as the difference between the realized volatility and the model-free risk-neutral integrated return volatility over the corresponding month. The risk-neutral volatility is obtained by the set of prices of options on each underlying individual security with one month to maturity. The numbers reported in Panel A are the average annualized $V R P$ for both the 20 portfolios and the S\&P 100 Index, the standard deviation of the VRP, the VRP-beta, and the relative bid-ask spread which is the average bid-ask spread for all traded options on the underlying stock that belong to a given portfolio calculated at the end of the last day of each month. Portfolio 1, P1VRP, contains the securities with the lowest $V R P$ betas and portfolio 20, P20VRP, includes securities with the highest $V R P$ betas. The portfolios are updated each month during the sample period. The VRP beta is the OLS regression coefficient from linear regressions of the monthly $V R P$ of each portfolio on the $V R P$ of the S\&P 100 market index. Panel B contains the annualized average return, the standard deviation of the returns, and the stock market betas of 20 portfolios computed with the same components as the portfolios in Panel A, The market return betas are the OLS regression coefficients from linear regressions of the monthly return of each portfolio on the market return index given by either the S\&P 100 Index or the overall US value-weight market return of all CRSP firms listed on the NYSE, AMEX, or NASDAQ. The betas are always estimated at the monthly frequency. 
Table 2

Factor Risk Loadings for Portfolio Returns Sorted by Volatility Risk Premium Betas: January 1996 to February 2011

Panel A: Fama and French Three-Factor Model Extended with Momentum and Quality Minus Junk

\begin{tabular}{|c|c|c|c|c|c|c|c|}
\hline & P1ER & P2ER & P3ER & P10ER & P18ER & P19ER & P20ER \\
\hline SMB & $\begin{array}{l}-0.100 \\
(-0.40)\end{array}$ & $\begin{array}{l}0.122 \\
(0.93)\end{array}$ & $\begin{array}{l}0.272 \\
(1.98)\end{array}$ & $\begin{array}{l}-0.034 \\
(-0.41)\end{array}$ & $\begin{array}{l}-0.289 \\
(-2.66)\end{array}$ & $\begin{array}{l}-0.391 \\
(-3.66)\end{array}$ & $\begin{array}{l}-0.311 \\
(-2.05)\end{array}$ \\
\hline HML & $\begin{array}{l}0.264 \\
(1.24)\end{array}$ & $\begin{array}{l}0.103 \\
(0.92)\end{array}$ & $\begin{array}{l}0.264 \\
(2.24)\end{array}$ & $\begin{array}{l}0.213 \\
(2.92)\end{array}$ & $\begin{array}{l}-0.070 \\
(-0.75)\end{array}$ & $\begin{array}{l}-0.020 \\
(-0.22)\end{array}$ & $\begin{array}{l}-0.142 \\
(-1.09)\end{array}$ \\
\hline MOM & $\begin{array}{l}-0.128 \\
(-0.98)\end{array}$ & $\begin{array}{l}-0.266 \\
(-3.84)\end{array}$ & $\begin{array}{l}-0.205 \\
(-2.82)\end{array}$ & $\begin{array}{l}-0.102 \\
(-2.25)\end{array}$ & $\begin{array}{l}-0.108 \\
(-1.88)\end{array}$ & $\begin{array}{l}-0.031 \\
(-054)\end{array}$ & $\begin{array}{l}-0.223 \\
(-2.77)\end{array}$ \\
\hline
\end{tabular}

Panel B: Fama and French Five-Factor Model

\begin{tabular}{|c|c|c|c|c|c|c|c|}
\hline & P1ER & P2ER & P3ER & P10ER & P18ER & P19ER & P20ER \\
\hline EMKET & $\begin{array}{l}1.288 \\
(7.24)\end{array}$ & $\begin{array}{c}1.123 \\
(11.54)\end{array}$ & $\begin{array}{c}1.097 \\
(11.05)\end{array}$ & $\begin{array}{c}1.100 \\
(18.01)\end{array}$ & $\begin{array}{c}1.126 \\
(14.26)\end{array}$ & $\begin{array}{c}1.199 \\
(15.58)\end{array}$ & $\begin{array}{c}1.336 \\
(12.15)\end{array}$ \\
\hline SMB & $\begin{array}{l}-0.066 \\
(-0.29)\end{array}$ & $\begin{array}{l}0.004 \\
(0.03)\end{array}$ & $\begin{array}{l}0.169 \\
(1.31)\end{array}$ & $\begin{array}{l}-0.097 \\
(-1.22)\end{array}$ & $\begin{array}{l}-0.271 \\
(-2.65)\end{array}$ & $\begin{array}{l}-0.347 \\
(-3.48)\end{array}$ & $\begin{array}{l}-0.336 \\
(-2.35)\end{array}$ \\
\hline HML & $\begin{array}{l}0.207 \\
(0.67)\end{array}$ & $\begin{array}{l}0.146 \\
(0.86)\end{array}$ & $\begin{array}{l}0.011 \\
(0.06)\end{array}$ & $\begin{array}{l}0.035 \\
(0.33)\end{array}$ & $\begin{array}{l}0.114 \\
(0.83)\end{array}$ & $\begin{array}{l}0.165 \\
(1.23)\end{array}$ & $\begin{array}{l}0.322 \\
(1.68)\end{array}$ \\
\hline CMA & $\begin{array}{l}0.147 \\
(0.34)\end{array}$ & $\begin{array}{l}-0.056 \\
(-0.24)\end{array}$ & $\begin{array}{l}0.370 \\
(1.53)\end{array}$ & $\begin{array}{l}0.271 \\
(1.81)\end{array}$ & $\begin{array}{l}-0.160 \\
(-0.83)\end{array}$ & $\begin{array}{l}-0.198 \\
(-1.05)\end{array}$ & $\begin{array}{l}-0.618 \\
(-2.30)\end{array}$ \\
\hline RMW & $\begin{array}{l}0.143 \\
(0.41)\end{array}$ & $\begin{array}{l}0.218 \\
(1.13)\end{array}$ & $\begin{array}{l}0.547 \\
(2.78)\end{array}$ & $\begin{array}{l}0.324 \\
(2.67)\end{array}$ & $\begin{array}{l}-0.261 \\
(-1.66)\end{array}$ & $\begin{array}{l}-0.295 \\
(-1.94)\end{array}$ & $\begin{array}{l}-0.439 \\
(-2.02)\end{array}$ \\
\hline
\end{tabular}

The volatility risk premium $(V R P)$ for each portfolio is defined as the difference between the realized volatility and the model-free risk-neutral integrated return volatility over the corresponding month. Portfolios P1ER to P20ER are return portfolios constructed with same underlying components employed in the VRP beta-sorted portfolios. The return portfolio 1, P1ER, contains the securities with the lowest VRP betas and the return portfolio 20, P20ER, includes securities with the highest VRP betas. The portfolios are updated each month during the sample period. This table contains the factor loadings estimated from regressions of monthly excess returns of seven representative portfolios on well known factor risks that include the five factors of the Fama-French five-factor model, the momentum factor and the quality minus junk factor. In Panel A, factor loadings are estimated using a multi-factor model with the Fama and French three-factor model extended with momentum and the quality minus junk factors. Panel B reports the factor loadings of the Fama-French five-factor model. Below the factor betas, and in parentheses, we report $t$-statistics. 
Table 3

Estimated Return Alphas of Representative Volatility Risk Premium Beta-Sorted Portfolios for Alternative Asset Pricing Models: January 1996 to February 2011

Estimated Alphas using 20 Volatility Risk Premium Beta-Sorted Portfolios

\begin{tabular}{|c|c|c|c|c|c|c|}
\hline $\begin{array}{l}\text { Representative } \\
\text { Portfolios }\end{array}$ & P1ER & P2ER & P10ER & P19ER & P20ER & P1ER-P20ER \\
\hline $\begin{array}{l}\text { FF 3-Factor } \\
\text { Model }\end{array}$ & $\begin{array}{l}0.0132 \\
(2.010) \\
{[1.659]}\end{array}$ & $\begin{array}{l}0.0118 \\
(3.071) \\
{[2.556]}\end{array}$ & $\begin{array}{l}0.0048 \\
(1.903) \\
{[1.906]}\end{array}$ & $\begin{array}{l}-0.0070 \\
(-2.275) \\
{[-2.035]}\end{array}$ & $\begin{array}{l}-0.0159 \\
(-3.603) \\
{[-3.737]}\end{array}$ & $\begin{array}{l}0.0292 \\
(3.351) \\
{[2.813]}\end{array}$ \\
\hline $\begin{array}{c}\text { FF 3-Factor } \\
\text { Model + MOM }\end{array}$ & $\begin{array}{l}0.0134 \\
(2.010) \\
{[1.667]}\end{array}$ & $\begin{array}{l}0.0135 \\
(3.569) \\
{[3.113]}\end{array}$ & $\begin{array}{l}0.0053 \\
(2.125) \\
{[2.005]}\end{array}$ & $\begin{array}{l}-0.0065 \\
(-2.109) \\
{[-1.874]}\end{array}$ & $\begin{array}{l}-0.0141 \\
(-3.250) \\
{[-2.848]}\end{array}$ & $\begin{array}{l}0.0276 \\
(3.148) \\
{[2.545]}\end{array}$ \\
\hline $\begin{array}{c}\text { FF 3-Factor } \\
\text { Model + MOM } \\
\text { + QMJ }\end{array}$ & $\begin{array}{l}0.0125 \\
(1.770) \\
{[1.473]}\end{array}$ & $\begin{array}{l}0.0108 \\
(2.719) \\
{[2.238]}\end{array}$ & $\begin{array}{l}0.0030 \\
(1.170) \\
{[1.197]}\end{array}$ & $\begin{array}{l}-0.0043 \\
(-1.317) \\
{[-1.122]}\end{array}$ & $\begin{array}{l}-0.0124 \\
(-2.702) \\
{[-2.551]}\end{array}$ & $\begin{array}{l}0.0250 \\
(2.692) \\
{[2.216]}\end{array}$ \\
\hline $\begin{array}{l}\text { FF 5-Factor } \\
\text { Model }\end{array}$ & $\begin{array}{l}0.0112 \\
(1.599) \\
{[1.163]}\end{array}$ & $\begin{array}{l}0.0109 \\
(2.676) \\
{[2.367]}\end{array}$ & $\begin{array}{l}0.0024 \\
(0.939) \\
{[1.006]}\end{array}$ & $\begin{array}{l}-0.0050 \\
(-1.541) \\
{[-1.426]}\end{array}$ & $\begin{array}{l}-0.0121 \\
(-2.621) \\
{[-2.513]}\end{array}$ & $\begin{array}{l}0.0232 \\
(2.545) \\
{[1.907]}\end{array}$ \\
\hline $\begin{array}{c}\text { FF 5-Factor } \\
\text { Model + MOM }\end{array}$ & $\begin{array}{l}0.0114 \\
(1.617) \\
\end{array}$ & $\begin{array}{l}0.0120 \\
(3.023) \\
{[2.712]}\end{array}$ & $\begin{array}{l}0.0028 \\
(1.103) \\
{[1.120]}\end{array}$ & $\begin{array}{l}-0.0047 \\
(-1.469) \\
{[-1.352]}\end{array}$ & $\begin{array}{l}-0.0111 \\
(-2.447) \\
{[-2.331]}\end{array}$ & $\begin{array}{l}0.0224 \\
(2.452) \\
{[1.825]}\end{array}$ \\
\hline
\end{tabular}

The volatility risk premium (VRP) for each portfolio is defined as the difference between the realized volatility and the model-free risk-neutral integrated return volatility over the corresponding month. The return portfolio 1 , P1ER, contains the securities with the lowest VRP betas and the return portfolio 20, P20ER, includes securities with the highest VRP betas. The portfolios are updated each month during the sample period. We estimate alphas using monthly returns for the full sample period, and alternative asset pricing specifications. $M O M$ is the momentum factor, and $Q M J$ is the quality minus junk factor of Asness, Frazzini, and Pedersen (2014). In parentheses, we report the OLS $t$-statistics, and in brackets we provide the Newey-West $t$-statistic. 
Table 4

Risk Premium Estimators for Alternative Factor Asset Pricing Models Using 40 Portfolios of Return and Volatility Risk Premia: January 1996 to February 2011

\begin{tabular}{|c|c|c|c|c|c|c|c|c|c|c|c|}
\hline Model 1 & $\begin{array}{c}0.003 \\
(0.005) \\
{[0.011]}\end{array}$ & $\begin{array}{c}0.009 \\
(0.027) \\
{[0.266]}\end{array}$ & - & - & - & - & - & $\begin{array}{c}-0.004 \\
(0.013) \\
{[0.200]}\end{array}$ & - & 0.006 & $\begin{array}{c}0.071 \\
(0.106) \\
{[0.164]}\end{array}$ \\
\hline Model 2 & $\begin{array}{c}0.005 \\
(0.001) \\
{[0.001]}\end{array}$ & - & $\begin{array}{c}-0.016 \\
(0.029) \\
{[0.432]}\end{array}$ & $\begin{array}{c}0.010 \\
(0.091) \\
{[0.429]}\end{array}$ & - & - & - & $\begin{array}{l}-0.006 \\
(0.001) \\
{[0.078]}\end{array}$ & - & 0.004 & $\begin{array}{c}0.055 \\
(0.152) \\
{[0.592]}\end{array}$ \\
\hline Model 3 & $\begin{array}{c}0.005 \\
(0.000) \\
{[0.000]}\end{array}$ & - & $\begin{array}{l}-0.015 \\
(0.031) \\
{[0.499]}\end{array}$ & $\begin{array}{c}0.012 \\
(0.051) \\
{[0.373]}\end{array}$ & $\begin{array}{l}-0.025 \\
(0.005) \\
{[0.203]}\end{array}$ & - & . & $\begin{array}{l}-0.006 \\
(0.001) \\
{[0.102]}\end{array}$ & - & 0.004 & $\begin{array}{c}0.065 \\
(0.146) \\
{[0.687]}\end{array}$ \\
\hline Model 4 & $\begin{array}{c}0.005 \\
(0.001) \\
{[0.006]}\end{array}$ & - & $\begin{array}{l}-0.013 \\
(0.066) \\
{[0.516]}\end{array}$ & $\begin{array}{c}0.008 \\
(0.183) \\
{[0.517]}\end{array}$ & $\begin{array}{l}-0.019 \\
(0.031) \\
{[0.308]}\end{array}$ & $\begin{array}{l}-0.020 \\
(0.074) \\
{[0.399]}\end{array}$ & - & $\begin{array}{l}-0.006 \\
(0.001) \\
{[0.119]}\end{array}$ & - & 0.004 & $\begin{array}{c}0.061 \\
(0.147) \\
{[0.793]}\end{array}$ \\
\hline Model 6 & $\begin{array}{c}0.007 \\
(0.000) \\
{[0.000]}\end{array}$ & $\begin{array}{l}-0.003 \\
(0.531) \\
{[0.732]}\end{array}$ & - & $\begin{array}{c}0.012 \\
(0.044) \\
{[0.430]}\end{array}$ & $\begin{array}{l}-0.032 \\
(0.000) \\
{[0.178]}\end{array}$ & - & - & $\begin{array}{l}-0.006 \\
(0.000) \\
{[0.081]}\end{array}$ & - & 0.005 & $\begin{array}{c}0.095 \\
(0.179) \\
{[0.463]}\end{array}$ \\
\hline Model 7 & $\begin{array}{c}0.005 \\
(0.000) \\
{[0.001]}\end{array}$ & $\begin{array}{c}0.005 \\
(0.228) \\
{[0.512]}\end{array}$ & - & - & - & - & - & $\begin{array}{l}-0.005 \\
(0.005) \\
{[0.108]}\end{array}$ & $\begin{array}{c}0.005 \\
(0.000) \\
{[0.001]}\end{array}$ & 0.004 & $\begin{array}{c}0.339 \\
(0.139) \\
{[0.000]}\end{array}$ \\
\hline Model 8 & $\begin{array}{c}0.006 \\
(0.000) \\
{[0.000]}\end{array}$ & - & $\begin{array}{l}-0.004 \\
(0.527) \\
{[0.802]}\end{array}$ & $\begin{array}{c}0.005 \\
(0.336) \\
{[0.613]}\end{array}$ & - & - & - & $\begin{array}{l}-0.005 \\
(0.001) \\
{[0.081]}\end{array}$ & $\begin{array}{c}0.005 \\
(0.000) \\
{[0.003]}\end{array}$ & 0.003 & $\begin{array}{c}0.331 \\
(0.148) \\
{[0.010]}\end{array}$ \\
\hline $\begin{array}{c}\text { Model } \\
12\end{array}$ & $\begin{array}{c}0.006 \\
(0.000) \\
{[0.000]}\end{array}$ & $\begin{array}{c}0.002 \\
(0.592) \\
{[0.755]}\end{array}$ & - & $\begin{array}{c}0.002 \\
(0.729) \\
{[0.872]}\end{array}$ & $\begin{array}{l}-0.007 \\
(0.337) \\
{[0.715]}\end{array}$ & - & - & $\begin{array}{l}-0.005 \\
(0.001) \\
{[0.047]}\end{array}$ & $\begin{array}{c}0.006 \\
(0.000) \\
{[0.002]}\end{array}$ & 0.004 & $\begin{array}{c}0.370 \\
(0.155) \\
{[0.004]}\end{array}$ \\
\hline $\begin{array}{c}\text { Model } \\
13\end{array}$ & $\begin{array}{c}0.009 \\
(0.000) \\
{[0.000]}\end{array}$ & - & - & - & - & - & - & $\begin{array}{l}-0.007 \\
(0.001) \\
{[0.041]}\end{array}$ & $\begin{array}{c}0.006 \\
(0.000) \\
{[0.001]}\end{array}$ & 0.004 & $\begin{array}{c}0.302 \\
(0.133) \\
{[0.002]}\end{array}$ \\
\hline $\begin{array}{c}\text { Model } \\
14\end{array}$ & $\begin{array}{c}0.008 \\
(0.000) \\
{[0.000]}\end{array}$ & - & - & - & - & $\begin{array}{c}0.004 \\
(0.740) \\
{[0.835]}\end{array}$ & - & $\begin{array}{l}-0.007 \\
(0.000) \\
{[0.057]}\end{array}$ & $\begin{array}{c}0.006 \\
(0.000) \\
{[0.001]}\end{array}$ & 0.004 & $\begin{array}{c}0.311 \\
(0.144) \\
{[0.007]}\end{array}$ \\
\hline $\begin{array}{c}\text { Model } \\
15\end{array}$ & $\begin{array}{c}0.009 \\
(0.000) \\
{[0.000]}\end{array}$ & - & - & - & - & - & $\begin{array}{l}-0.005 \\
(0.572) \\
{[0.703]}\end{array}$ & $\begin{array}{l}-0.007 \\
(0.000) \\
{[0.045]}\end{array}$ & $\begin{array}{c}0.005 \\
(0.000) \\
{[0.002]}\end{array}$ & 0.004 & $\begin{array}{c}0.301 \\
(0.140) \\
{[0.004]}\end{array}$ \\
\hline
\end{tabular}

This table reports the two-pass cross-sectional regression risk premium estimators from the 40 portfolios of return and volatility risk premia data using alternative asset pricing models. These 40 portfolios sort assets by the volatility risk premium betas. Below all risk premium estimators, we report the $p$-values associated with the traditional Fama-MacBeth standard error in parentheses and in brackets, the $p$-values of the standard errors adjusted for errors-in-variable and the potential misspecification of the model. $M A E$ is the mean absolute pricing error and the last column reports the $R^{2}$ where below we display the standard error and in brackets the $p$ value for the test of the null hypothesis that the $R^{2}$ is equal to zero. 
Table 5

Risk Premium Estimators for the Fama and French Five-Factor Model Using 40 Portfolios of Return and Volatility Risk Premia: January 1996 to February 2011

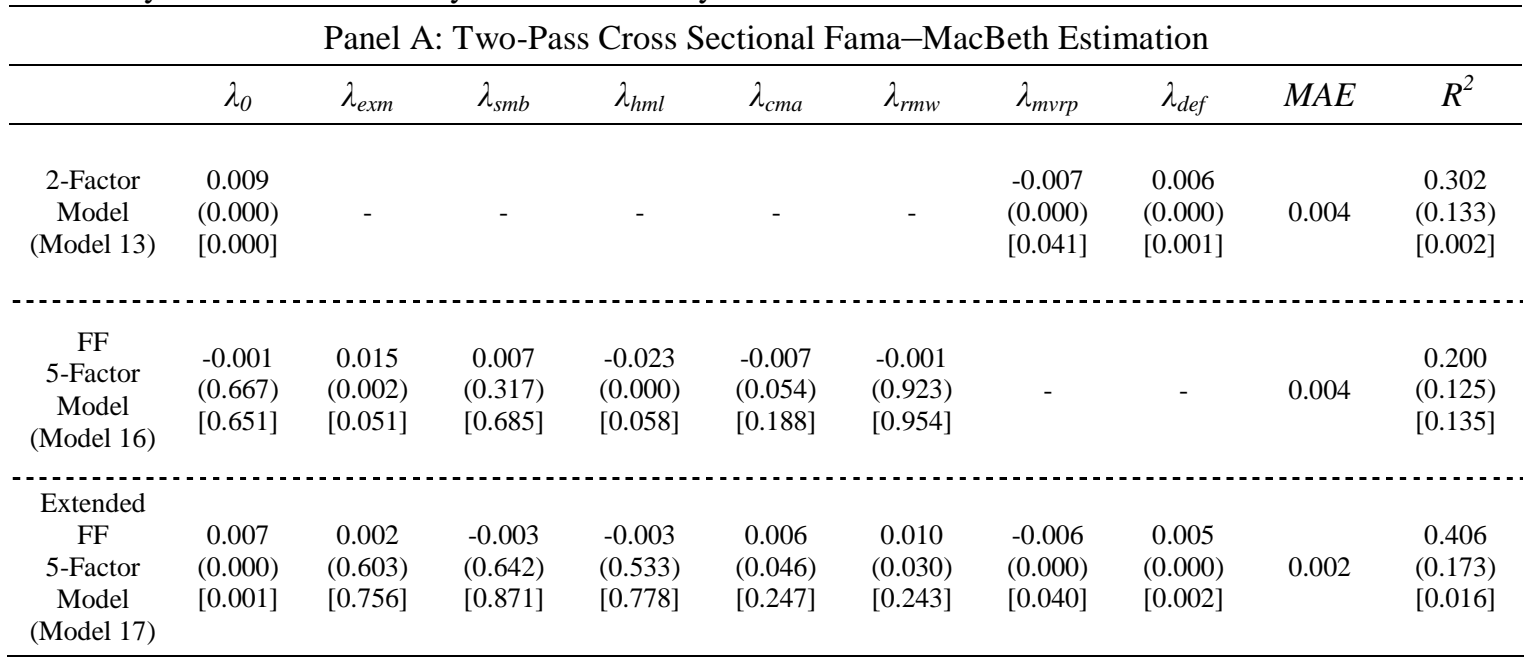

This table reports the two-pass cross-sectional regression risk premium estimators from the 40 portfolios of return and volatility risk premia data. These 40 portfolios sort assets by the volatility risk premium betas. We compare the results from the two-factor model with the market volatility risk premium, and the default spread with the Fama-French five-factor model. Below all risk premium estimators, we report the $p$-values associated with the traditional Fama-MacBeth standard error in parentheses and in brackets, the $p$ values of the standard errors adjusted for errors-in-variable and the potential misspecification of the model. $M A E$ is the mean absolute pricing error and the last column reports the $R^{2}$ where below we display the standard error and in brackets the $p$-value for the test of the null hypothesis that the $R^{2}$ is equal to zero. 
Table 6

Risk Premium Estimators for the Two-Factor Model Extended with Alternative Measures of Funding Liquidity and the Leverage Factor Using 40 Portfolios of Return and Volatility Risk Premia: January 1996 to February 2011

\begin{tabular}{|c|c|c|c|c|c|c|c|c|}
\hline & $\lambda_{0}$ & $\lambda_{m v r p}$ & $\lambda_{\text {def }}$ & $\lambda_{l e v}$ & $\lambda_{\text {ted }}$ & $\lambda_{f l}$ & $M A E$ & $R^{2}$ \\
\hline Model 13 & $\begin{array}{c}0.009 \\
(0.000) \\
{[0.000]}\end{array}$ & $\begin{array}{l}-0.007 \\
(0.001) \\
{[0.041]}\end{array}$ & $\begin{array}{c}0.006 \\
(0.000) \\
{[0.001]}\end{array}$ & - & - & - & 0.004 & $\begin{array}{c}0.302 \\
(0.133) \\
{[0.002]}\end{array}$ \\
\hline Model 18 & $\begin{array}{c}0.006 \\
(0.000) \\
{[0.000]}\end{array}$ & $\begin{array}{l}-0.006 \\
(0.001) \\
{[0.085]}\end{array}$ & - & $\begin{array}{c}0.007 \\
(0.159) \\
{[0.498]}\end{array}$ & - & - & 0.006 & $\begin{array}{c}0.071 \\
(0.191) \\
{[0.155]}\end{array}$ \\
\hline Model 19 & $\begin{array}{c}0.009 \\
(0.000) \\
{[0.000]}\end{array}$ & $\begin{array}{l}-0.007 \\
(0.001) \\
{[0.066]}\end{array}$ & - & - & $\begin{array}{c}0.002 \\
(0.009) \\
{[0.107]}\end{array}$ & - & 0.006 & $\begin{array}{c}0.108 \\
(0.191) \\
{[0.204]}\end{array}$ \\
\hline Model 20 & $\begin{array}{c}0.005 \\
(0.005) \\
{[0.000]}\end{array}$ & $\begin{array}{l}-0.004 \\
(0.049) \\
{[0.199]}\end{array}$ & - & - & - & $\begin{array}{l}-0.128 \\
(0.048) \\
{[0.079]}\end{array}$ & 0.005 & $\begin{array}{c}0.114 \\
(0.052) \\
{[0.145]}\end{array}$ \\
\hline Model 21 & $\begin{array}{c}0.006 \\
(0.000) \\
{[0.000]}\end{array}$ & $\begin{array}{l}-0.005 \\
(0.002) \\
{[0.055]}\end{array}$ & $\begin{array}{c}0.006 \\
(0.000) \\
{[0.006]}\end{array}$ & $\begin{array}{c}0.008 \\
(0.086) \\
{[0.396]}\end{array}$ & - & - & 0.004 & $\begin{array}{c}0.357 \\
(0.168) \\
{[0.001]}\end{array}$ \\
\hline Model 22 & $\begin{array}{c}0.007 \\
(0.000) \\
{[0.000]}\end{array}$ & $\begin{array}{l}-0.006 \\
(0.002) \\
{[0.032]}\end{array}$ & $\begin{array}{c}0.005 \\
(0.000) \\
{[0.000]}\end{array}$ & - & $\begin{array}{c}0.001 \\
(0.425) \\
{[0.555]}\end{array}$ & - & 0.004 & $\begin{array}{c}0.347 \\
(0.174) \\
{[0.006]}\end{array}$ \\
\hline Model 23 & $\begin{array}{c}0.008 \\
(0.000) \\
{[0.000]}\end{array}$ & $\begin{array}{l}-0.006 \\
(0.003) \\
{[0.051]}\end{array}$ & $\begin{array}{c}0.006 \\
(0.000) \\
{[0.001]}\end{array}$ & - & - & $\begin{array}{l}-0.112 \\
(0.063) \\
{[0.120]}\end{array}$ & 0.004 & $\begin{array}{c}0.339 \\
(0.190) \\
{[0.001]}\end{array}$ \\
\hline Model 24 & $\begin{array}{c}0.006 \\
(0.000) \\
{[0.000]}\end{array}$ & $\begin{array}{l}-0.005 \\
(0.004) \\
{[0.055]}\end{array}$ & $\begin{array}{c}0.005 \\
(0.000) \\
{[0.001]}\end{array}$ & $\begin{array}{c}0.010 \\
(0.047) \\
{[0.335]}\end{array}$ & $\begin{array}{c}0.001 \\
(0.245) \\
{[0.466]}\end{array}$ & - & 0.004 & $\begin{array}{c}0.391 \\
(0.164) \\
{[0.005]} \\
0 . . . . . . ~\end{array}$ \\
\hline Model 25 & $\begin{array}{c}0.006 \\
(0.000) \\
{[0.000]}\end{array}$ & $\begin{array}{l}-0.005 \\
(0.009) \\
{[0.075]}\end{array}$ & $\begin{array}{c}0.006 \\
(0.000) \\
{[0.001]}\end{array}$ & $\begin{array}{c}0.009 \\
(0.037) \\
{[0.312]}\end{array}$ & - & $\begin{array}{l}-0.015 \\
(0.775) \\
{[0.828]}\end{array}$ & 0.003 & $\begin{array}{c}0.385 \\
(0.163) \\
{[0.000]}\end{array}$ \\
\hline Model 26 & $\begin{array}{c}0.005 \\
(0.000) \\
{[0.000]}\end{array}$ & $\begin{array}{c}-0.004 \\
(0.019) \\
{[0.100]}\end{array}$ & $\begin{array}{c}0.005 \\
(0.000) \\
{[0.001]}\end{array}$ & $\begin{array}{c}0.012 \\
(0.011) \\
{[0.228]}\end{array}$ & $\begin{array}{c}0.001 \\
(0.336) \\
{[0.543]}\end{array}$ & $\begin{array}{c}-0.002 \\
(0.971) \\
{[0.978]}\end{array}$ & 0.003 & $\begin{array}{c}0.402 \\
(0.164) \\
{[0.005]}\end{array}$ \\
\hline
\end{tabular}

This table reports the two-pass cross-sectional regression risk premium estimators from the 40 portfolios of return and volatility risk premia data. These 40 portfolios sort assets by the volatility risk premium betas. The cross-sectional tests include the leverage factor mimicking portfolio of brokers-dealers of Adrian, Etula, and Muir (2014), the TED spread as the difference between the LIBOR and the T.bill rates, and the funding liquidity measure of Fontaine and García (2012) which reflects the age-based measure of liquidity from U.S. Treasuries. Below all risk premium estimators, we report the $p$-values associated with the traditional Fama-MacBeth standard error in parentheses and in brackets, the $p$-values of the standard errors adjusted for errors-in-variable and the potential misspecification of the model. MAE is the mean absolute pricing error and the last column reports the $R^{2}$ where below we display the standard error and in brackets the $p$-value for the test of the null hypothesis that the $R^{2}$ is equal to zero. 
Table 7

Risk Premium Estimators for Alternative Factor Asset Pricing Models with Variance Risk Premium Using 40 Portfolios of Return and Variance Risk Premia: January 1996 to February 2011

\begin{tabular}{|c|c|c|c|c|c|c|c|c|c|c|c|c|c|}
\hline & $\lambda_{0}$ & $\lambda_{\text {exm }}$ & $\lambda_{s m b}$ & $\lambda_{h m l}$ & $\lambda_{\text {mom }}$ & $\lambda_{c m a}$ & $\lambda_{r m w}$ & $\lambda_{\text {mvarrp }}$ & $\lambda_{\text {def }}$ & $\lambda_{l e v}$ & $\lambda_{\text {ted }}$ & $M A E$ & $R^{2}$ \\
\hline $\begin{array}{c}\text { Model } \\
13\end{array}$ & $\begin{array}{c}0.006 \\
(0.011) \\
{[0.014]}\end{array}$ & & & & & & & $\begin{array}{c}-0.033 \\
(0.000) \\
{[0.000]}\end{array}$ & $\begin{array}{c}0.005 \\
(0.000) \\
{[0.003]}\end{array}$ & & & 0.004 & $\begin{array}{c}0.293 \\
(0.131) \\
{[0.001]}\end{array}$ \\
\hline $\begin{array}{c}\text { Model } \\
12 \\
\end{array}$ & $\begin{array}{c}0.006 \\
(0.001) \\
{[0.028]}\end{array}$ & $\begin{array}{l}0.0002 \\
(0.903) \\
{[0.935]}\end{array}$ & & $\begin{array}{c}0.008 \\
(0.118) \\
{[0.432]}\end{array}$ & $\begin{array}{l}-0.017 \\
(0.025) \\
{[0.328]}\end{array}$ & & & $\begin{array}{l}-0.033 \\
(0.000) \\
{[0.000]}\end{array}$ & $\begin{array}{c}0.005 \\
(0.000) \\
{[0.004]}\end{array}$ & & & 0.003 & $\begin{array}{c}0.311 \\
(0.150) \\
{[0.012]}\end{array}$ \\
\hline $\begin{array}{c}\text { Model } \\
17\end{array}$ & $\begin{array}{c}0.006 \\
(0.005) \\
{[0.114]}\end{array}$ & $\begin{array}{c}0.003 \\
(0.460) \\
{[0.612]}\end{array}$ & $\begin{array}{c}-0.004 \\
(0.568) \\
{[0.759]}\end{array}$ & $\begin{array}{l}-0.002 \\
(0.654) \\
{[0.819]}\end{array}$ & & $\begin{array}{c}0.006 \\
(0.038) \\
{[0.240]}\end{array}$ & $\begin{array}{c}0.010 \\
(0.028) \\
{[0.070]}\end{array}$ & $\begin{array}{l}-0.034 \\
(0.000) \\
{[0.000]}\end{array}$ & $\begin{array}{c}0.004 \\
(0.000) \\
{[0.010]}\end{array}$ & & & 0.002 & $\begin{array}{c}0.396 \\
(0.148) \\
{[0.010]}\end{array}$ \\
\hline
\end{tabular}

This table reports the results from cross-sectional regressions using the variance risk premium instead of the volatility risk premium. The variance risk premium for each portfolio is defined as the difference between the realized variance and the model-free risk-neutral integrated return variance over the corresponding month. The risk-neutral variance is obtained by the set of prices of options on each underlying individual security with one month to maturity. We employ 40 portfolios constructed on the basis of the variance risk premium betas. We employ simultaneously 20 portfolios of variance risk premia, and 20 return portfolios with the same components as the variance risk premium portfolios. This table reports the two-pass cross-sectional regression risk premium estimators from the 40 portfolios We compare the results from the two-factor model with the market variance risk premium, and the default spread (Model 13) with a five-factor model that includes the excess market return, the $H M L$ and $M O M$ factors, extended with the market variance risk premium, and the default spread (Model 12). We also test the Fama-French five-factor model extended with the market variance risk premium, and the default spread (Model 17). Below all risk premium estimators, we report the $p$-values associated with the traditional Fama-MacBeth standard error in parentheses and in brackets, the $p$-values of the standard errors adjusted for errorsin-variable and the potential misspecification of the model. $M A E$ is the mean absolute pricing error and the last column reports the $R^{2}$ where below we display the standard error and in brackets the $p$-value for the test of the null hypothesis that the $R^{2}$ is equal to zero. 
Table 8

Risk Premium Estimators for Alternative Factor Asset Pricing Models with 20 Volatility Risk Premium Portfolios, and 20 Return Portfolios. All Portfolios Sorted by the Volatility Risk Premium Betas: January 1996 to February 2011

Panel A: 20 Volatility Risk Premia Portfolios

\begin{tabular}{|c|c|c|c|c|c|c|c|c|c|c|c|c|c|}
\hline & $\lambda_{0}$ & $\lambda_{\text {exm }}$ & $\lambda_{s m b}$ & $\lambda_{h m l}$ & $\lambda_{\text {mom }}$ & $\lambda_{c m a}$ & $\lambda_{r m w}$ & $\lambda_{m v r p}$ & $\lambda_{\text {def }}$ & $\lambda_{\text {lev }}$ & $\lambda_{\text {ted }}$ & $M A E$ & $R^{2}$ \\
\hline $\begin{array}{c}\text { Model } \\
13\end{array}$ & $\begin{array}{c}0.007 \\
(0.000) \\
{[0.006]}\end{array}$ & & & & & & & $\begin{array}{l}-0.006 \\
(0.000) \\
{[0.049]}\end{array}$ & $\begin{array}{c}0.012 \\
(0.000) \\
{[0.000]}\end{array}$ & & & 0.002 & $\begin{array}{c}0.514 \\
(0.211) \\
{[0.001]}\end{array}$ \\
\hline $\begin{array}{c}\text { Model } \\
12 \\
\end{array}$ & $\begin{array}{c}0.008 \\
(0.000) \\
{[0.018]}\end{array}$ & $\begin{array}{l}-0.017 \\
(0.019) \\
{[0.388]}\end{array}$ & & $\begin{array}{c}0.018 \\
(0.009) \\
{[0.338]}\end{array}$ & $\begin{array}{c}-0.021 \\
(0.041) \\
{[0.656]}\end{array}$ & & & $\begin{array}{c}-0.009 \\
(0.000) \\
{[0.017]}\end{array}$ & $\begin{array}{c}0.010 \\
(0.000) \\
{[0.001]}\end{array}$ & & & 0.001 & $\begin{array}{c}0.547 \\
(0.213) \\
{[0.038]}\end{array}$ \\
\hline $\begin{array}{c}\text { Model } \\
17 \\
\end{array}$ & $\begin{array}{c}0.010 \\
(0.000) \\
{[0.166]}\end{array}$ & $\begin{array}{l}-0.014 \\
(0.026) \\
{[0.746]}\end{array}$ & $\begin{array}{l}-0.030 \\
(0.001) \\
{[0.685]}\end{array}$ & $\begin{array}{c}0.018 \\
(0.006) \\
{[0.386]}\end{array}$ & & $\begin{array}{c}-0.003 \\
(0.430) \\
{[0.834]}\end{array}$ & $\begin{array}{c}0.056 \\
(0.000) \\
{[0.032]}\end{array}$ & $\begin{array}{l}-0.006 \\
(0.001) \\
{[0.406]}\end{array}$ & $\begin{array}{c}0.009 \\
(0.000) \\
{[0.038]}\end{array}$ & & & 0.001 & $\begin{array}{c}0.771 \\
(0.224) \\
{[0.162]}\end{array}$ \\
\hline $\begin{array}{c}\text { Model } \\
24\end{array}$ & $\begin{array}{c}0.009 \\
(0.000) \\
{[0.001]}\end{array}$ & & & & & & & $\begin{array}{l}-0.005 \\
(0.004) \\
{[0.095]}\end{array}$ & $\begin{array}{c}0.010 \\
(0.000) \\
{[0.000]}\end{array}$ & $\begin{array}{c}0.006 \\
(0.430) \\
{[0.877]}\end{array}$ & $\begin{array}{c}0.000 \\
(0.625) \\
{[0.833]}\end{array}$ & 0.002 & $\begin{array}{c}0.660 \\
(0.217) \\
{[0.007]} \\
\end{array}$ \\
\hline
\end{tabular}

Panel B: 20 Equity Return Portfolios

\begin{tabular}{|c|c|c|c|c|c|c|c|c|c|c|c|c|c|}
\hline & $\lambda_{0}$ & $\lambda_{\text {exm }}$ & $\lambda_{s m b}$ & $\lambda_{h m l}$ & $\lambda_{\text {mom }}$ & $\lambda_{\text {cma }}$ & $\lambda_{r m w}$ & $\lambda_{m v r p}$ & $\lambda_{\text {def }}$ & $\lambda_{\text {lev }}$ & $\lambda_{\text {ted }}$ & $M A E$ & $R^{2}$ \\
\hline $\begin{array}{c}\text { Model } \\
13\end{array}$ & $\begin{array}{c}0.017 \\
(0.000) \\
{[0.000]}\end{array}$ & & & & & & & $\begin{array}{c}0.003 \\
(0.219) \\
{[0.311]}\end{array}$ & $\begin{array}{c}0.005 \\
(0.000) \\
{[0.001]}\end{array}$ & & & 0.003 & $\begin{array}{c}0.367 \\
(0.292) \\
{[0.030]}\end{array}$ \\
\hline $\begin{array}{c}\text { Model } \\
12\end{array}$ & $\begin{array}{c}0.028 \\
(0.000) \\
{[0.133]}\end{array}$ & $\begin{array}{l}-0.014 \\
(0.040) \\
{[0.133]}\end{array}$ & & $\begin{array}{l}-0.006 \\
(0.302) \\
{[0.524]}\end{array}$ & $\begin{array}{c}0.011 \\
(0.157) \\
{[0.349]}\end{array}$ & & & $\begin{array}{c}0.003 \\
(0.234) \\
{[0.346]}\end{array}$ & $\begin{array}{c}0.004 \\
(0.000) \\
{[0.003]}\end{array}$ & & & 0.002 & $\begin{array}{c}0.620 \\
(0.225) \\
{[0.034]}\end{array}$ \\
\hline $\begin{array}{c}\text { Model } \\
17\end{array}$ & $\begin{array}{c}0.026 \\
(0.000) \\
{[0.004]}\end{array}$ & $\begin{array}{l}-0.012 \\
(0.086) \\
{[0.141]}\end{array}$ & $\begin{array}{c}0.010 \\
(0.149) \\
{[0.558]}\end{array}$ & $\begin{array}{l}-0.004 \\
(0.532) \\
{[0.715]}\end{array}$ & & $\begin{array}{c}0.005 \\
(0.125) \\
{[0.237]}\end{array}$ & $\begin{array}{l}-0.001 \\
(0.762) \\
{[0.819]}\end{array}$ & $\begin{array}{c}0.001 \\
(0.644) \\
{[0.716]}\end{array}$ & $\begin{array}{c}0.004 \\
(0.001) \\
{[0.062]}\end{array}$ & & & 0.002 & $\begin{array}{c}0.678 \\
(0.252) \\
{[0.121]}\end{array}$ \\
\hline $\begin{array}{c}\text { Model } \\
24\end{array}$ & $\begin{array}{c}0.016 \\
(0.000) \\
{[0.003]}\end{array}$ & & & & & & & $\begin{array}{c}0.006 \\
(0.025) \\
{[0.134]}\end{array}$ & $\begin{array}{c}0.004 \\
(0.000) \\
{[0.001]}\end{array}$ & $\begin{array}{c}0.002 \\
(0.723) \\
{[0.843]}\end{array}$ & $\begin{array}{c}0.000 \\
(0.391) \\
{[0.475]}\end{array}$ & 0.003 & $\begin{array}{c}0.579 \\
(0.304) \\
{[0.060]}\end{array}$ \\
\hline
\end{tabular}

This table reports the results from cross-sectional regressions using separately 20 portfolios of volatility risk premia, and 20 return portfolios with the same components as the volatility risk premium portfolios. Panel A reports the two-pass cross-sectional regression risk premium estimators from the 20 volatility risk premium portfolios, and Panel B displays the two-pass cross-sectional regression risk premium estimators from the 20 equity return portfolios We compare the results from the two-factor model with the market volatility risk premium, and the default spread (Model 13) with a fivefactor model that includes the excess market return, the $H M L$ and $M O M$ factors, extended with the market volatility risk premium, and the default spread (Model 12). We also test the Fama-French five-factor model extended with the market volatility risk premium, and the default spread (Model 17), and the two-factor model extended with the leverage factor and TED as a proxy for funding liquidity (Model 24). Below all risk premium estimators, we report the $p$-values associated with the traditional Fama-MacBeth standard error in parentheses and in brackets, the $p$-values of the standard errors adjusted for errors-in-variable and the potential misspecification of the model. MAE is the mean absolute pricing error and the last column reports the $R^{2}$ where below we display the standard error and in brackets the $p$-value for the test of the null hypothesis that the $R^{2}$ is equal to zero. 
Table 9

Wald Tests for Risk Premia Equality from Two-Pass Cross-Sectional Regression Estimation for Alternative Asset Pricing Models with 20 Volatility Risk Premia Portfolios, and 20 Return Portfolios. All Portfolios Sorted by the Volatility Risk Premium Betas: January 1996 to February 2011

\begin{tabular}{|c|c|c|c|c|c|c|c|c|c|c|c|}
\hline & $\lambda_{0}$ & $\lambda_{\text {exm }}$ & $\lambda_{s m b}$ & $\lambda_{h m l}$ & $\lambda_{\text {mom }}$ & $\lambda_{c m a}$ & $\lambda_{r m w}$ & $\lambda_{\text {vrpm }}$ & $\lambda_{d e f}$ & $\lambda_{\text {lev }}$ & $\lambda_{\text {ted }}$ \\
\hline $\begin{array}{c}\text { Model } \\
13\end{array}$ & $\begin{array}{l}-2.090 \\
(0.037)\end{array}$ & & & & & & & $\begin{array}{l}-2.071 \\
(0.038)\end{array}$ & $\begin{array}{c}2.400 \\
(0.016)\end{array}$ & & \\
\hline $\begin{array}{c}\text { Model } \\
12\end{array}$ & $\begin{array}{l}-2.029 \\
(0.042)\end{array}$ & $\begin{array}{c}-0.128 \\
(0.898)\end{array}$ & & $\begin{array}{c}1.138 \\
(0.255)\end{array}$ & $\begin{array}{l}-0.666 \\
(0.505)\end{array}$ & & & $\begin{array}{c}-2.370 \\
(0.018)\end{array}$ & $\begin{array}{c}1.853 \\
(0.064)\end{array}$ & & \\
\hline $\begin{array}{c}\text { Model } \\
17\end{array}$ & $\begin{array}{l}-1.431 \\
(0.152)\end{array}$ & $\begin{array}{c}-0.051 \\
(0.959)\end{array}$ & $\begin{array}{c}-0.529 \\
(0.597)\end{array}$ & $\begin{array}{c}0.937 \\
(0.349)\end{array}$ & & $\begin{array}{l}-0.552 \\
(0.581)\end{array}$ & $\begin{array}{c}2.135 \\
(0.033)\end{array}$ & $\begin{array}{l}-0.900 \\
(0.368)\end{array}$ & $\begin{array}{c}1.143 \\
(0.253)\end{array}$ & & \\
\hline $\begin{array}{c}\text { Model } \\
24\end{array}$ & $\begin{array}{l}-1.173 \\
(0.241)\end{array}$ & & & & & & & $\begin{array}{l}-2.177 \\
(0.029)\end{array}$ & $\begin{array}{c}2.128 \\
(0.033)\end{array}$ & $\begin{array}{c}0.104 \\
(0.917)\end{array}$ & $\begin{array}{l}-0.145 \\
(0.885)\end{array}$ \\
\hline
\end{tabular}

This table reports the results from Wald tests to statistically check whether the risk premia are significantly equal across alternative asset pricing models and both sets of return and volatility portfolios. We compare the results from the two-factor model with the market volatility risk premium, and the default spread (Model 13) with a five-factor model that includes the excess market return, the $H M L$ and $M O M$ factors, extended with the market volatility risk premium, and the default spread (Model 12). We also test the Fama-French five-factor model extended with the market volatility risk premium, and the default spread (Model 17), and the two-factor model extended with the leverage factor and TED as a proxy for funding liquidity (Model 24). 
Table 10

Mean-Adjusted $R$-Squares as Indicators of Pricing Integration between 20 Volatility Risk Premium Portfolios, and 20 Return Portfolios: January 1996 to February 2011

\begin{tabular}{|c|c|c|c|c|}
\hline \multirow[b]{2}{*}{ Year } & \multicolumn{2}{|c|}{$\begin{array}{c}\text { Panel A: All Portfolios Sorted by } \\
\text { Volatility Risk Premium Betas }\end{array}$} & \multicolumn{2}{|c|}{$\begin{array}{l}\text { Panel B: All Portfolios Sorted by } \\
\text { Market Return Betas }\end{array}$} \\
\hline & $\begin{array}{l}\text { Mean-Adjusted } R \text { - } \\
\text { Squares for } \\
20 \text { VRP Portfolios } \\
\text { Related to Common }\end{array}$ & $\begin{array}{l}\text { Mean-Adjusted } R \text { - } \\
\text { Squares for } \\
\text { 20 Return Portfolios } \\
\text { Related to Common }\end{array}$ & $\begin{array}{c}\text { Mean-Adjusted } R \text { - } \\
\text { Squares for } \\
20 \text { VRP Portfolios } \\
\text { Related to Common }\end{array}$ & $\begin{array}{c}\text { Mean-Adjusted } R \text { - } \\
\text { Squares for } \\
\text { 20 Return Portfolios } \\
\text { Related to Common }\end{array}$ \\
\hline 1997 & 0.894 & 0.640 & 0.783 & 0.531 \\
\hline 1998 & 0.941 & 0.651 & 0.886 & 0.626 \\
\hline 1999 & 0.893 & 0.528 & 0.789 & 0.472 \\
\hline 2000 & 0.935 & 0.456 & 0.810 & 0.417 \\
\hline 2001 & 0.941 & 0.575 & 0.866 & 0.455 \\
\hline 2002 & 0.930 & 0.713 & 0.894 & 0.628 \\
\hline 2003 & 0.770 & 0.707 & 0.738 & 0.673 \\
\hline 2004 & 0.834 & 0.595 & 0.674 & 0.585 \\
\hline 2005 & 0.862 & 0.559 & 0.715 & 0.493 \\
\hline 2006 & 0.899 & 0.550 & 0.742 & 0.540 \\
\hline 2007 & 0.937 & 0.747 & 0.865 & 0.520 \\
\hline 2008 & 0.966 & 0.814 & 0.970 & 0.770 \\
\hline 2009 & 0.887 & 0.762 & 0.815 & 0.703 \\
\hline 2010 & 0.941 & 0.808 & 0.907 & 0.780 \\
\hline 2011 & 0.923 & 0.613 & 0.879 & 0.579 \\
\hline Average & 0.903 & 0.648 & 0.822 & 0.585 \\
\hline
\end{tabular}

This table reports the average estimated $R$-squares as a measure of market integration for return and volatility portfolios. We estimate seven out-of-sample principal components as the proxies for common factors in the 40 portfolios of equities and volatilities. These estimated common factors are the explanatory variables of a series of regressions, one for each available portfolio of either $V R P$ or returns in each year from 1997 to 2011 . We run these 40 regressions with daily data, and we estimate the adjusted $R$-square of each regression and, therefore, for each of the 40 portfolios. In each year, we take the average of these $R$-squares across the $20 \mathrm{VRP}$ portfolios and the average of the $R$-squares across the 20 equity portfolios. The first column contains the averages of the estimated $R$-squares on yearly basis for the $20 \mathrm{VRP}$ portfolios. Similarly, the second column displays the yearly averages estimated $R$-squares for the 20 equity portfolios. Panel A reports the results for all 40 portfolios sorted by volatility risk premium betas, while Panel B contains the result for all 40 portfolios sorted by market return betas. 
Figure 1

Volatility Risk Premia Across Volatility Risk Premium Beta-Sorted Portfolios and the Market Volatility Risk Premium: January 1996 to February 2011

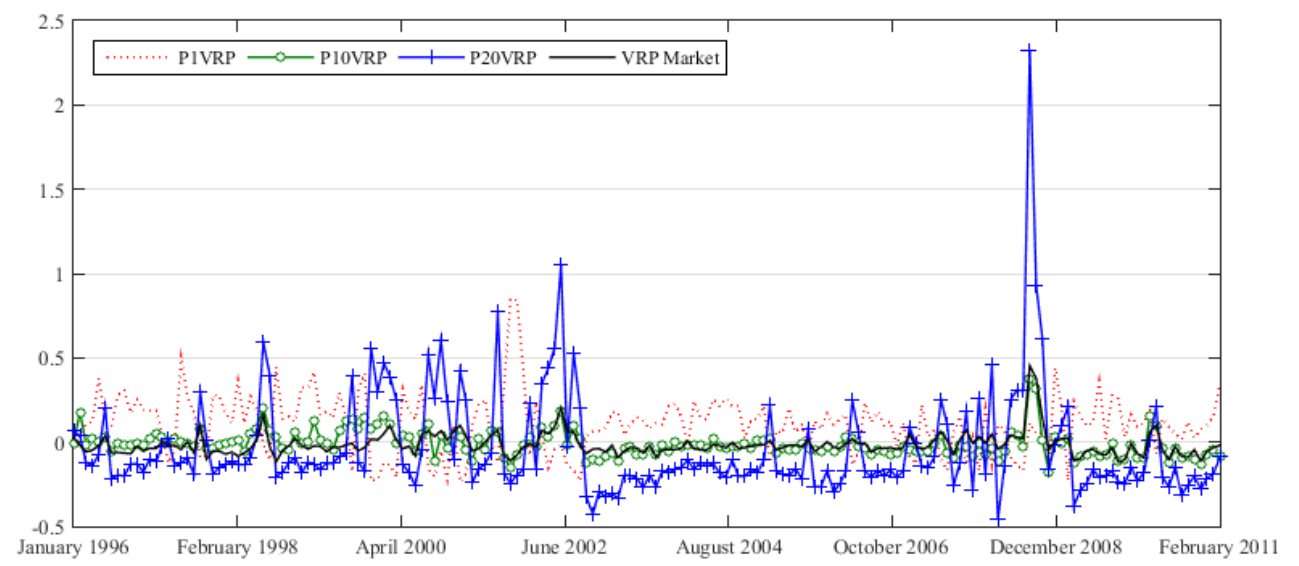

This figure displays the temporal behavior of the representative volatility risk premium beta-sorted portfolios and the market volatility risk premium. 
Figure 2

Panel A: Market Price of Risk of the Market Volatility Risk Premium for 20 Volatility Risk Premium Portfolios, and 20 Return Portfolios. All Portfolios Sorted by Volatility Risk Premium Betas: January 1996 to February 2011

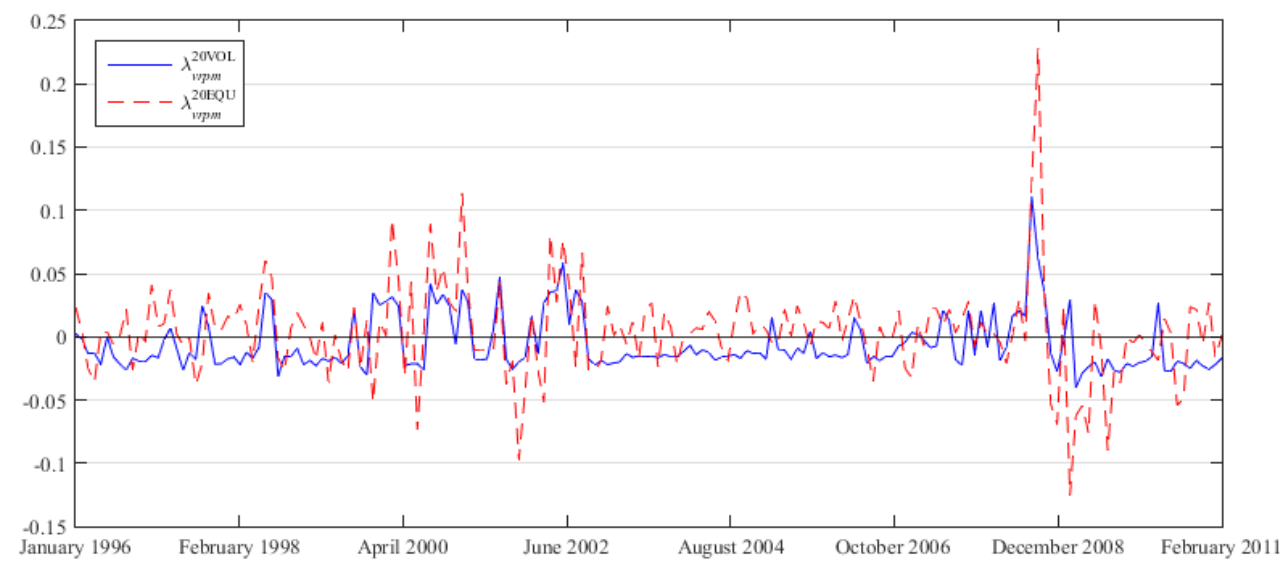

Panel B: Market Price of Risk of the Default Risk Premium for 20 Volatility Risk Premium Portfolios, and 20 Return Portfolios. All Portfolios Sorted by Volatility Risk Premium Betas: January 1996 to February 2011

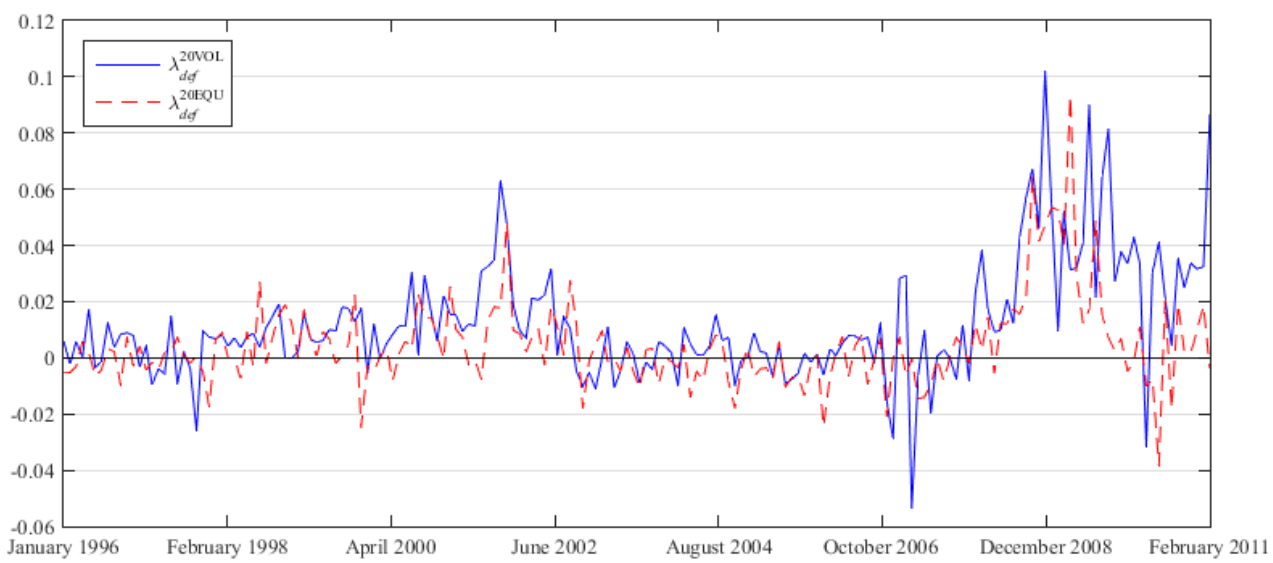


Figure 3

Panel A: Density Functions of Market Price of Risk of the Market Volatility Risk Premium for 20 Volatility Risk Premium Portfolios, and 20 Return Portfolios: January 1996 to February 2011

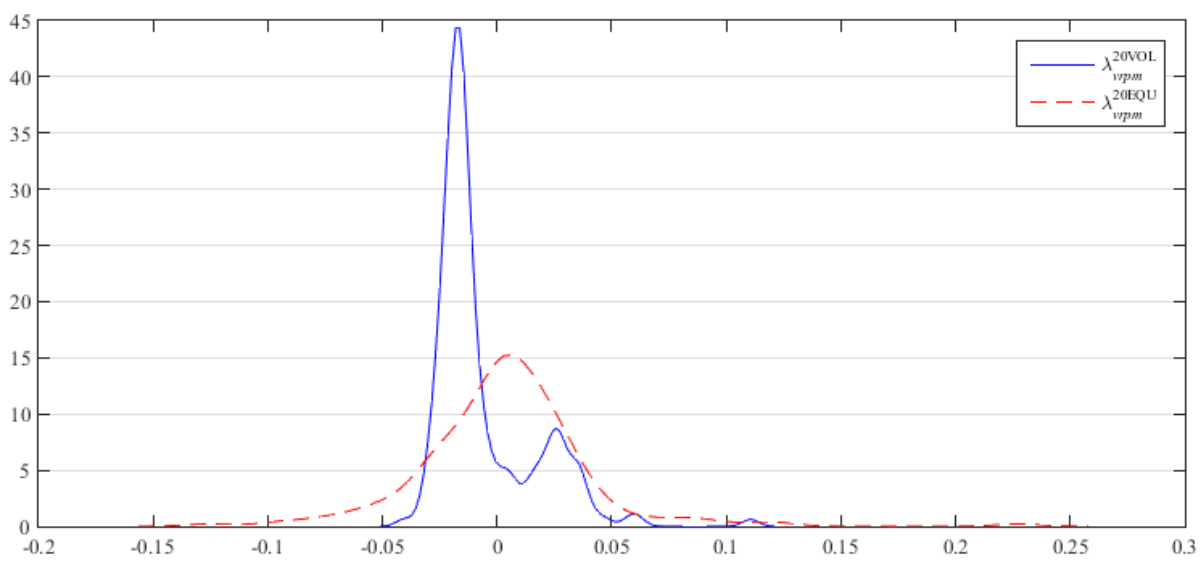

Panel B: Density Functions of Market Price of Risk of the Default Risk Premium for 20 Volatility Risk Premium Portfolios, and 20 Return Portfolios: January 1996 to February 2011

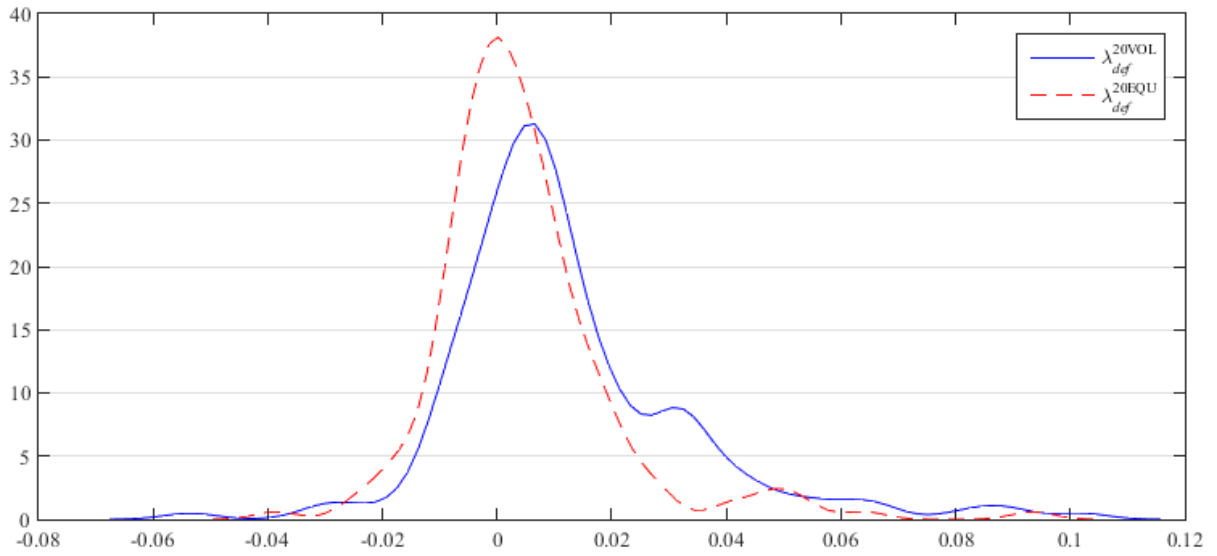


Figure 4

Panel A: Mean Adjusted R-Squares as Measures of Pricing Integration for Volatility and Return Portfolios. All Portfolios Sorted by Volatility Risk Premium Betas: January 1996 to February 2011

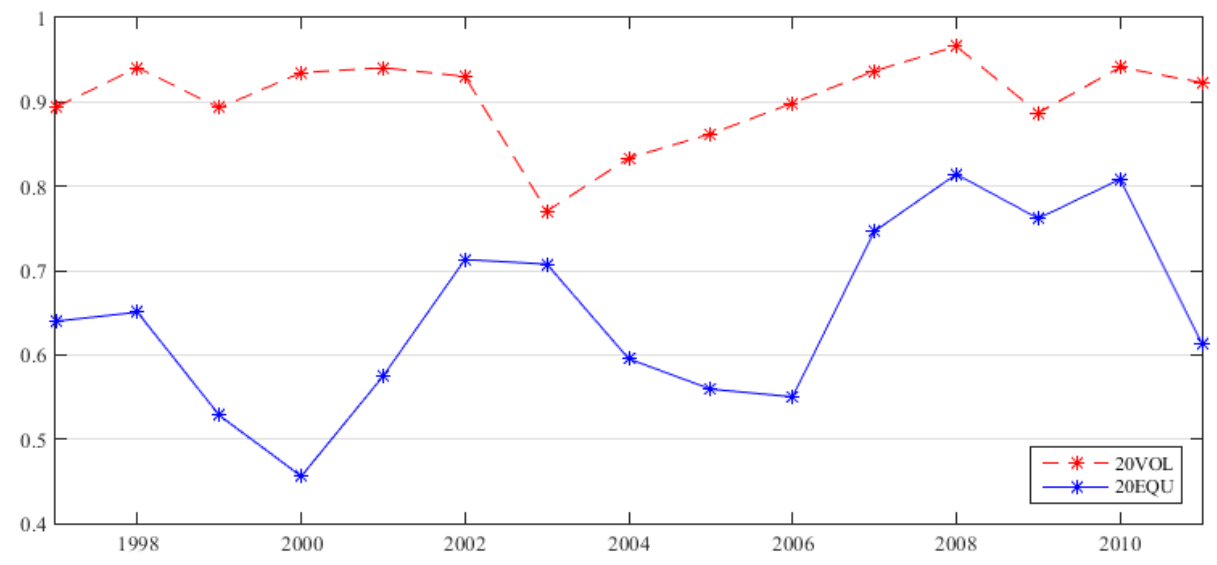

Panel B: Mean Adjusted $R$-Squares as Measures of Pricing Integration for Volatility and Return Portfolios. All Portfolios Sorted by Market Return Betas: January 1996 to February 2011

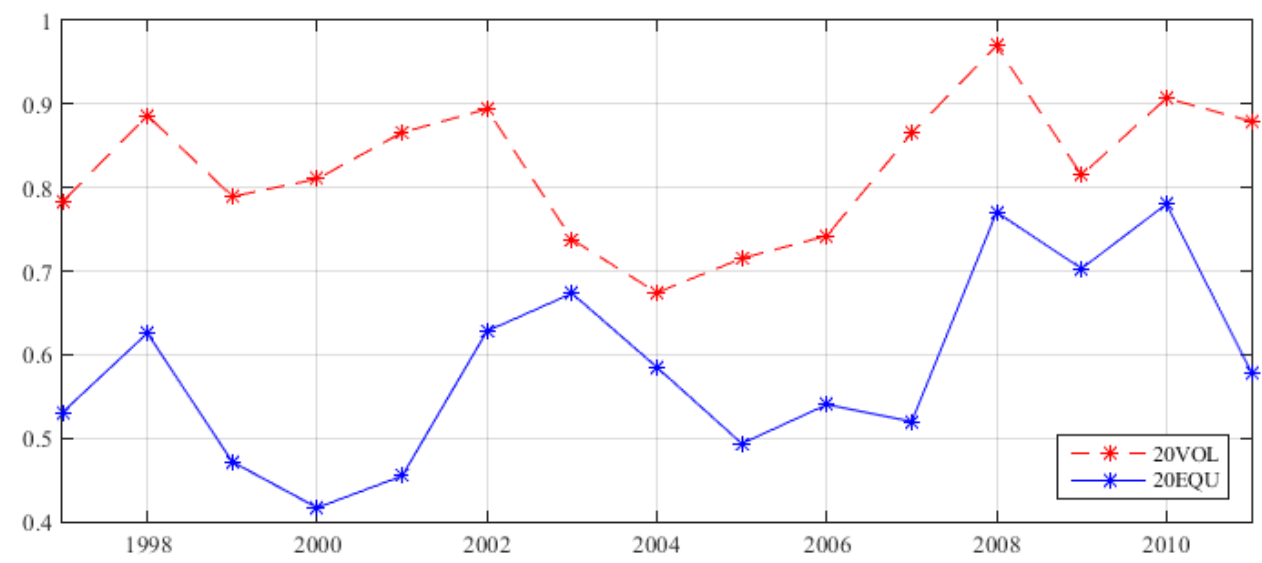

